\title{
The relationship between equity and bond returns: An empirical investigation
}

\author{
Amer Demirovic ${ }^{\mathrm{a}}$, Cherif Guermat ${ }^{\mathrm{b}}$ and Jon Tucker ${ }^{\mathrm{b}, *}$ \\ ${ }^{a}$ Sarajevo School of Science and Technology, Hrasnička cesta 3a, Sarajevo, 71 000, \\ Bosnia and Herzegovina \\ ${ }^{\mathrm{b}}$ Centre for Global Finance, Faculty of Business \& Law, University of the West of England, \\ Frenchay Campus, Coldharbour Lane, Bristol BS16 1QY, United Kingdom
}

\begin{abstract}
The correlation between equity and corporate debt is ambiguous. News affecting the value of a firm's assets induces a positive correlation, whereas an increase in the volatility of a firm's assets induces a negative correlation. We examine the conditional correlation between these two securities. While the average correlation is positive, the conditional correlation increases with credit risk, and decreases with equity volatility. Our results are consistent with the thesis that the equity bond relation is dependent on the potential wealth transfer between stock and debt holders. Nevertheless, this relation seems to break down during periods of extreme market uncertainty.
\end{abstract}

Keywords:

Equity-bond correlation; distance to default; equity volatility

JEL classification:

G11; G12; G14

* Corresponding author. Tel.: +44(0)1173283754; fax: +44(0)1173282289.

Email addresses: amer.demirovic@ssst.edu.ba (A. Demirovic), Cherif.Guermat@uwe.ac.uk (C. Guermat), Jon.Tucker@uwe.ac.uk (J.Tucker) 


\section{Introduction}

The correlation between the equity and bond returns of a firm (henceforth EBR correlation) is puzzling. On the one hand, equity and debt securities have different claims on the same assets. As noted by Campbell and Taksler (2003), shareholder action can be detrimental to the claim of the bondholders, which implies a negative correlation between equity and bond returns. On the other hand, the equity and debt instruments issued by a firm are in general exposed to the same market risks. Since both classes of securities are exposed to the same risk inherent in the firm's assets, their values should be systematically and positively correlated in complete markets.

The structural model of Merton (1974) shows that there is a formal relation between the values of equity and debt. The former is equal to the value of a call option written on the value of a firm's assets. The value of a corporate bond is equal to that of a risk-free bond less the value of a put option written on the firm's assets. Merton's model therefore points to drivers of the correlation between equity and bond returns. The first driver is a firm's earnings potential, which is a major determinant of the value of its assets. A drop in the firm's earnings potential negatively impacts its equity value. It also has negative implications for the value of the firm's bonds as the lower earnings potential implies potential future problems with bond repayment. As the values of both securities should move in the same direction, the contemporaneous correlation is expected to be positive and significant. Furthermore, the correlation should be stronger for firms with a greater possibility of default.

A change in the volatility of a firm's assets does not affect overall firm value but exerts different effects on the values of equity and debt. In a zero-sum game, equity holders benefit from an increase in volatility while corresponding losses are inflicted on debt holders. Therefore, contrary to a change in the value of assets, an increase in the volatility of a firm's assets induces a negative 
contemporaneous correlation between the values of equity and debt securities (Campbell and Taksler, 2003).

The evidence on firm-level correlation is very limited. The vast majority of studies focus on the relation between government or aggregate bond yields and aggregate equity returns. Gulko (2002) and Connolly, Stivers, and Sun (2005), for example, provide evidence that the government bondequity correlation turns from positive to negative during market crises. Baele, Bekaert, and Inghelbrecht (2010) document that the correlation between daily returns on equity and bond indices varies significantly over time. These studies in general provide evidence of the flight-tosafety phenomenon or the investor preference for safe assets during market declines, but tell us little about the firm-level links between equity and corporate bonds.

Baker and Wurgler (2012) take a different approach and look at the relation between government bonds and the cross-section of stocks. Their results suggest that government bonds covary more with low-risk bonds, which implies that the correlation between the returns on corporate bonds and equities depends on the credit risk exposure of firms. However, the bond index in Baker and Wurgler (2012) acts as a common factor to all stocks. As a result, the implied link between stocks and bonds at the firm level is both limited and indirect. In this paper, we take a different perspective by considering the cross-section of both stocks and corporate bonds on a peer-to-peer basis. By doing so, we are able to uncover a richer set of links between firm-level bonds and stocks compared to those explored in aggregate stock-bond studies.

Studies that have considered the firm-level stock-bond correlation include Kwan (1996), Campbell and Taksler (2003), and Cremers et al. (2008). However, these studies have focused on examining the unconditional correlation between the credit spread or the bond yield and the variables included in the structural model of Merton (1974). They provide evidence on the sign of 
the correlation between firm-level equity and corporate bonds, but tell us little about its time variation and dependence on firm risk. There are just a few studies that examine the conditional correlation between firm-level equities and corporate bonds (or credit default swaps). For example, Scheicher (2009) and Belke and Gokus (2011) match limited samples of equities and credit default swaps.

We contribute to the literature by examining how changes in firm-level equity volatility and credit risk affect the correlation. Unlike previous studies, we estimate the distance to default (DD) of Merton (1974) to control for credit risk, which is crucial if the correlation depends on the riskiness of firms as implied by the structural model, and is demonstrated by the empirical studies given above. We also depart from the firm-level literature by examining how a common aggregate factor, namely the VIX index, affects the relation between the firm-level variables and the correlation. This market outlook index turns out to be an important moderator for the effects of firm-specific risk characteristics.

Consistent with previous studies, we find that the correlation is on average positive, which implies that the price variation of these two securities is more often due to changes in the value of the underlying assets rather than management action that causes a wealth transfer between stock and debt holders. The correlation strongly depends on credit risk. It is high when credit risk is high and rapidly decreases as firms become safer. When we control for credit risk, the relation between equity volatility and the correlation is negative, as implied by the structural model. This relation between the correlation and the firm-level risk factors dramatically weakens when market risk is elevated. The correlation is higher when market risk is high, but it is primarily driven by changes in common, rather than firm-level, risk factors. To our knowledge, we are the first to provide a link between firm level and aggregate market level risk characteristics, as well as to show how 
aggregate market conditions moderate the implications of the structural model of Merton (1974) at the firm level.

The remainder of this paper is divided into five sections. In the following section, we review relevant studies and develop the hypotheses. In Section 3, we describe the data and present the methodology for estimating EBR correlation, measures of equity volatility and credit risk, and the empirical model specifications. The results are presented in Section 4, and the robustness of the results is examined in Section 5. The main conclusions are summarized in Section 6.

\section{Literature review and development of hypotheses}

The structural model of Merton (1974) describes the theoretical relation between the value of a firm's assets and the values of the securities issued by the firm. Merton shows that the value of equity equals the value of a call option, whereas the value of debt is equal to the value of risk-free debt less a put option written on the value of the firm's assets. The strike price of both options is the value of debt.

The structural model implies that a change in the value of a firm's assets causes a positive correlation between the returns on equity and debt. A change in the value of assets, ceteris paribus, affects the value of equity and debt in the same direction. An increase in the value of assets, for instance, is beneficial to equity holders as the growth in the underlying stock price is beneficial for an investor who purchased a call option. An increase in the value of assets also supports the value of debt by lowering the firm's leverage and, consequently, the probability of default. These two mechanisms taken together give rise to a positive correlation between equity and debt returns.

In contrast, a change in the volatility of a firm's assets has an opposing effect on the values on equity and debt as equity holders stand to benefit from the upside potential of more volatile assets, 
whereas debt holders face an increased default probability as assets with higher volatility are more likely to fall to the value of debt and trigger bankruptcy. As a result, an increase in the volatility of assets induces a negative correlation between the values of equity and debt.

Thus, the correlation between equity and bond returns may be either positive or negative, depending on whether new information about a firm primarily affects the value of its assets or the volatility of those assets. Kwan (1996) examines the bond yields and equity returns of 327 firms over the 1986-1990 period. He reports a negative correlation between firm-level equity returns and bond yields. Since bond yields and bond returns move in opposite directions, this finding implies a positive correlation between equity and bond returns. Hotchkiss and Ronen (2002) examine returns on 55 high-yield bonds and corresponding firm equities. They find equity returns to be significant in explaining only the returns on the lowest rated bonds (i.e., B- and lower) in their sample. Norden and Weber (2007) analyze the intertemporal relation between credit default swaps, equities, and bonds. They analyze data for 58 firms over the 2000-2002 period, and report that the relation between equity returns and bond spreads (bond returns) is significant and negative (positive).

A negative correlation is generally found to be caused by an agency conflict whereby managers take actions that increase equity value at the expense of debt value. An example of such action is share repurchases. Maxwell and Stephens (2003) find that around share repurchase announcements, equity returns are abnormally positive while bond returns are negative. Alexander, Edwards and Ferri (2000) also confirm that the correlation between equity and bond returns at times turns negative around events that are beneficial to equity holders (e.g., issuing debt or adopting risky projects) or debt holders (paying down debt or diversifying assets). Since takeovers, particularly if funded by debt, negatively affect the value of existing debt, Bhanot, 
Mansi, and Wald (2010) find that takeover risk also has a negative effect on the correlation between equity and bond returns.

The firm-level analysis differs in many ways from the aggregate level analysis. A flight to safety at an aggregate level indicates movement from one market to another, but it does not inform us whether such a movement is uniform across all firms, or whether some firms experience more movement than others. Similarly, the so-called decoupling of stock and bond markets might not translate into the decoupling between stocks and bonds at the firm level. The more interesting disaggregation to the cross-section of stocks by Baker and Wurgler (2012) does tell us something about the connection between individual stocks and government bonds, and implies a strong connection between bond-like stocks and bonds (relative to speculative stocks). However, while the cross-section analysis of stocks does provide some insight into the pricing of stocks, it is not directly relevant for the pricing of individual bonds. Moreover, there is more to pricing individual bonds than can be drawn from the government bond versus individual stocks relation. More formally, both stocks and bonds should be priced as the expected present value of their future cash flows. Baker and Wurgler (2012, p. 59) state that "bonds and bond-like stocks are clearly exposed to common shocks to real cash flows." This, however, ignores the option features of both assets, as well as the potential conflict between bond holders and equity holders. Our results show that the expected cash flows of bonds and stocks (regardless of their grade) might not be necessarily linked at all, and may even be negatively linked. Thus, we argue that the aggregate stock-bond analysis does not filter down to the firm level. 


\subsection{The average correlation}

Most of the empirical evidence suggests that the correlation between equity and bond returns is positive, but turns negative around wealth-transferring events such as leveraged buyouts. Since the wealth-transferring events are relatively infrequent, their effect on the correlation between equity and bond returns should not be dominant over the medium to long term. Therefore, the following hypothesis is stated:

H1: The average correlation between equity and bond returns is positive.

In contrast to previous studies that typically conduct the empirical testing by regressing bond yields on equity returns, this study proceeds with empirical testing in two steps. First, the conditional correlation between equity and bond returns is estimated in a bivariate GARCH model. Second, the statistical significance of the coefficients in the covariance equations is examined, and the hypothesis is formally tested that the mean of the conditional correlation series is positive and significantly different from zero.

\subsection{Credit risk and correlation}

The structural model implies that the level of credit risk is the most important determinant of the strength of correlation between equity and bond returns. As previously discussed, a small change in the value of the equity or equity volatility of high-quality firms has a limited impact on the firm's default probability. However, as the default probability increases, its sensitivity to changes in any fundamental variable increases too. This is generally confirmed by the empirical studies that commonly use credit ratings to control for credit risk. Kwan (1996) finds that the returns on AAA-bonds approach the risk-free rate, while the returns on non-investment grade bonds are highly correlated with the returns of the corresponding firm equities. Hotchkiss and 
Ronen (2002) find that the correlation between equity and bond returns is only statistically significant when they control for credit risk. Similarly, Cheyette and Tomaich (2003) report that the bond yields of high-quality issuers are primarily explained by changes in the risk-free rate, while the bond yields of firms with lower credit quality are determined by equity returns. Surprisingly, the bond yields of firms with intermediate credit quality are not related to either interest rate factors or equity returns.

Scheicher (2009) finds leverage (as measured by balance sheet total debt to total assets) to be an insignificant determinant of conditional correlations between equity returns and changes in the credit default swap premium. Campbell and Taksler (2003) also use accounting leverage ratios to control for credit risk in their analysis of the determinants of credit spreads. They could not confirm the prediction of the structural model that the importance of equity volatility in determining credit spreads increases with credit risk. Similarly, Cremers et al. (2008) obtain inconsistent results with the prediction of the structural model when using credit ratings to control for credit risk. Thus, both theoretical and empirical results point to the following hypothesis:

H2: The strength of correlation between equity and bond returns depends on the level of a firm's credit risk. More specifically, the greater the firm's risk, the higher the correlation. Moreover, low-risk firms should evidence low or no correlation.

\subsection{The impact of equity volatility on EBR correlation}

As noted above, the structural model of Merton (1974) predicts that an increase in the volatility of a firm's asset induces a negative correlation, which leads to the following hypothesis:

H3: Equity volatility has a negative impact on the correlation between equity and bond returns. 
There is little empirical evidence to support this hypothesis. Scheicher (2009) analyzes the determinants of conditional correlations between stock returns and changes in credit default swap (CDS) premia for a sample of 129 U.S. firms. He reports that equity volatility has a negative impact on the correlation between equity returns and CDS premia. Since CDS premia and bond returns are negatively related, his finding implies that equity volatility has a positive effect on the correlation. This result, which is inconsistent with the predictions of the structural model, is probably caused by a weak control for the level of credit risk, which we address in Hypotheses 2 and 4 .

\subsection{The interaction between equity volatility and the distance to default}

Hypothesis 3 states that equity volatility impacts negatively on the correlation between equity and bond returns. Rather than being linear, this relation is expected to strengthen as credit risk increases. Therefore, there should be a significant interaction effect between equity volatility and the distance to default. A change in equity volatility should exert a disproportionately strong effect on the correlation for firms on the brink of bankruptcy, and almost no impact on the correlation of returns of very safe firms. Campbell and Taksler (2003) and Cremers et al. (2008) provide some evidence of this effect, but do not obtain a monotonic relation between the level of credit risk and the effect of equity volatility on the credit spread. These inconclusive results are likely to be caused by weak proxies for credit risk (they use an accounting-based ratio and firm credit ratings) and data samples populated mainly by investment-grade firms.

Consistent with theory, prior empirical results generally show that the economic impact of equity volatility on the credit spread increases as the distance to default falls (Campbell and 
Taksler, 2003; Cremers et al., 2008). Therefore, we hypothesize that the same effect holds for the correlation between equity and bond returns:

H4: The economic impact of equity volatility on the correlation between equity and bond returns increases as the distance to default falls.

\section{Methodology}

In this section we provide a brief account on various definitions and approaches used to compute returns, conditional correlation, the distance to default, and bond issue characteristics. We then describe the empirical model.

\subsection{Equity and bond returns}

Equity returns are calculated in the usual manner. Define $P_{i, t}^{E}$ as the share price of firm $i$ at time $t$, and $D_{i, t}$ as dividends paid from time $t-1$ to time $t$. The rate of return is defined as:

$$
R_{i, t}^{E}=\ln \frac{P_{i, t}^{E}+D_{i, t}}{P_{i, t-1}^{E}}
$$

The holding-period returns for bonds are calculated in a similar manner. Define $P_{i, t}^{B}$ as the bond price of firm $i$ at time $t, C_{i, t}$ as the coupon payments, and $A C_{i, t}$ as the accrued interest on bond $i$ from time $t-1$ to time $t$. The rate of return is defined as:

$$
R_{i, t}^{B}=\ln \frac{P_{i, t}^{B}+C_{i, t}+A C_{i, t}}{P_{i, t-1}^{B}+A C_{i, t-1}}
$$




\subsection{Conditional correlation between equity and bond returns}

The conditional correlation between equity and bond returns is obtained from a bivariate Generalized Autoregressive Conditional Heteroscedasticity (GARCH) process. The mean equations are given by:

$$
R_{t}^{E}=c_{1}+\varepsilon_{E, t} \text { and } R_{t}^{B}=c_{2}+\varepsilon_{B, t} \text {, }
$$

where $R_{t}^{E}, R_{t}^{B}, \varepsilon_{E, t}$, and $\varepsilon_{B, t}$ are equity and bond returns, and the disturbance terms, respectively. One of the most popular models for estimating the conditional covariance is Bollerslev, Engle, and Wooldridge (1988). We use the parsimonious version referred to as the diagonal VECH $(1,1)$. In order to guarantee that the conditional covariance matrix is positive semi-definite, we follow Engle and Kroner (1995) and Ding and Engle (2001), and restrict the coefficient matrices to rank 1 matrices. This gives the following variance/covariance equations:

$$
\begin{aligned}
& h_{E, t}=c_{1}+a_{1} \varepsilon_{E, t-1}^{2}+b_{1} h_{E, t-1} \\
& h_{B, t}=c_{2}+a_{2} \varepsilon_{B, t-1}^{2}+b_{2} h_{B, t-1} \\
& h_{E B, t}=c_{1} c_{2}+a_{1} a_{2} \varepsilon_{E, t-1}^{2} \varepsilon_{B, t-1}^{2}+b_{1} b_{2} h_{E B, t-1},
\end{aligned}
$$

where $h_{E, t}, h_{B, t}$, and $h_{E B, t}$ are, respectively, the equity variance, the bond variance, and the equitybond covariance. This specification is widely utilized in empirical studies (e.g., Bekaert and $\mathrm{Wu}$, 2000; Ang and Chen, 2002; Belke and Gokus, 2011). In the above specification, we assume that the variances and the covariance respond symmetrically to positive and negative news. This assumption can be relaxed by extending the variance and covariance equations with an additional asymmetric term. Thus, the asymmetric model is given by: 


$$
\begin{aligned}
& h_{E, t}=c_{1}+a_{1} \varepsilon_{E, t-1}^{2}+b_{1} h_{E, t-1}+d_{1} \varepsilon_{E, t-1}^{2} I_{E, t-1} \\
& h_{B, t}=c_{2}+a_{2} \varepsilon_{B, t-1}^{2}+b_{2} h_{B, t-1}+d_{1} \varepsilon_{B, t-1}^{2} I_{B, t-1} \\
& h_{E B, t}=c_{1} c_{2}+a_{1} a_{2} \varepsilon_{E, t-1}^{2} \varepsilon_{B, t-1}^{2}+ \\
& b_{1} b_{2} h_{E B, t-1}+d_{1} d_{2} \varepsilon_{E, t-1}^{2} I_{E, t-1} \varepsilon_{B, t-1}^{2} I_{B, t-1}
\end{aligned}
$$

where $I_{t-1}=1$ if $\varepsilon_{t-1}<0$ and zero otherwise.

\subsection{Distance to default}

The distance to default (DD) is the difference between the market value of the assets and the book value of debt relative to the volatility of the market value of the assets (Merton, 1974). DD follows directly from the Black and Scholes (1973) call option pricing equation:

$$
E=A N\left(d_{1}\right)-D e^{-r T} N\left(d_{2}\right)
$$

where

$$
d_{1}=\frac{\ln \left(\frac{\mathrm{A}}{D}\right)+\left(r+\frac{\sigma_{A}^{2}}{2}\right) T}{\sigma_{A} \sqrt{T}}
$$

$d_{2}=d_{1}-\sigma_{A} \sqrt{T}, E$, and $A$ are the market values of the firm's equity and assets, $\sigma_{A}$ is the volatility of the market value of the firm's assets, $D$ is the book value of the firm's debt, $r$ is the risk-free rate, $T$ is the time horizon in years, and $N($.$) is the cumulative density of the standard normal$ distribution. 
The market value of the firm's assets is assumed to follow a geometric Brownian motion process. Assuming that the firm's equity value follows the same process, its dynamics under the risk-neutral probability measure can be described by:

$$
d E=r E d t+\sigma_{E} E d X
$$

where $\sigma_{E}$ is the volatility of the market value of the firm's equity and $d X_{t}$ is the standard Wiener process. Since the equity value is a function of the asset value and time, Itô's lemma can be applied to give:

$$
d E=\left[\frac{\partial E}{\partial t}+r A \frac{\partial E}{\partial A}+\frac{1}{2}\left(\sigma_{A} A\right)^{2} \frac{\partial^{2} E}{\partial A^{2}}\right] d t+\frac{\partial E}{\partial A} \sigma_{A} A d X
$$

A comparison of the coefficient multiplying the stochastic components in the two preceding equations gives the following identity:

$$
\sigma_{E} E=\frac{\partial E}{\partial A} A \sigma_{A}
$$

The unobservable market value and volatility of the firm's assets are estimated by simultaneously solving equations (6) and (9). This approach is widely used in empirical studies (e.g., Ronn and Verma, 1986; Hillegeist et al., 2004; Campbell, Hilscher, and Szilagyi, 2008). The equity volatility is estimated using a $\operatorname{GARCH}(1,1)$ model (Bollerslev, 1986). Once the asset value and volatility are estimated, the distance to default is calculated as follows:

$$
D D=\frac{\ln \left(\frac{\mathrm{A}}{\bar{D}}\right)+\left(r-\frac{\sigma_{A}^{2}}{2}\right) T}{\sigma_{A} \sqrt{T}} .
$$




\subsection{Bond issue characteristics}

To control for the maturity of bonds, daily duration is calculated according to the following formula:

$$
d=\frac{1}{B_{d}} \sum_{t=1}^{N} \frac{C F_{t}}{(1+Y)^{t}} t
$$

where $B_{d}$ is the dirty bond price (clean price + accrued interest), $C F_{t}$ is the cash flow in period $t$, $N$ is the number of periods to maturity, and $Y$ is the per-period yield to maturity. The control variable for the size of the bond issue is the natural logarithm of the bond's market price multiplied by the number of outstanding bonds.

\subsection{Panel data analysis}

The data set consists of the conditional correlation between equity and bond returns, and a set of independent variables for $n$ firms over $T$ consecutive time periods. Because of the possible common factors influencing the correlation, we use a panel data model with period fixed effects:

$$
C_{i t}=\alpha_{t}+\beta x_{i t}+\varepsilon_{i t}, \quad \varepsilon_{i t} \sim i . i . d .\left(0, \sigma^{2}\right),
$$

where $C_{i t}$ is the conditional correlation between the equity and bond returns of firm $i$ at time $t, \alpha_{t}$ is the period effect, $\beta$ is a $k \times 1$ parameter vector, $x_{i t}$ is a vector of $k$ explanatory variables, and $\varepsilon_{i t}$ is a disturbance term.

Our hypotheses are tested by regressing the conditional correlation between equity and bond returns, $C_{i t}$, on specific regressors. For Hypothesis 3, we use the firm's (conditional) equity 
volatility, $V_{i t}$, obtained from a GARCH process. Since the structural model implies that the effect of volatility is not monotonic, we include a quadratic term to account for potential non-linearity.

Hypotheses 2 and 4 concern the distance to default, $D D_{i t}$, of Merton (1974). As discussed above, it is expected that the impact of a change in DD strongly depends on the level of credit risk. In other words, a small change in a large DD should have only a limited impact on the correlation between equity and bond returns, while the magnitude of impact should grow as DD falls. Our model accounts for this non-linearity with the squared DD variable. Moreover, there might also be a discrete form of non-linearity in the impact of changes in DD. Investors might not think of the riskiness of a firm as a continuous variable. Rather, they might perceive a firm as being on a scale containing a limited number of risk classes, say ranging from very safe to highly risky. It may be the case that investors follow the popular discrete approach used by credit rating agencies. It could also be the case that investors make use of simple rules of thumb to make decisions (Gigerenzer and Goldstein, 1996). To account for this possibility, we employ DD dummies, $D D_{i t}^{S}=I\left(\tau_{s} \leq\right.$ $\left.D D_{i t}<\tau_{s+1}\right)$, where $I($.$) is the indicator function and \tau_{s}$ are thresholds.

Determining the number of dummies and the threshold values is not straightforward. Dealing with a single threshold is already quite complex (Hansen, 2000), and we are not aware of a methodology that can consistently and simultaneously estimate the optimal number of dummies and their associated thresholds. In this paper, we take a simple approach. The dummies and thresholds are determined by estimating models with different sets of dummies and threshold values and selecting the model on the basis of a minimum Akaike information criterion (AIC). Specifically, for each number of dummies $(s=1, \ldots, n)$, we estimate models for all threshold combinations (with discrete increment steps). For the DD variable, we estimated 4,753 models. The lowest AIC is achieved with 15 dummies, but $94 \%$ of the improvement in AIC is achieved by 
a set of four dummies. Therefore, in order to have as parsimonious a model as possible, we use the optimal set of four dummy variables: $0.8,1.8,2.8$, and 3.8. In the Appendix, we provide a more detailed explanation of the selection procedure.

The coefficient of $D D_{i t}$ then captures the average effect of the DD, while the dummy coefficients capture the additional effect of the DD for predefined risk classes. If Hypothesis 2 holds, the dummy coefficients should be statistically significant and monotonically increasing in size as the predefined thresholds of DD decrease (i.e., as the level of credit risk increases).

Hypothesis 4 is examined by including an interaction term between volatility and the $\mathrm{DD}, V_{i t} D D_{i t}$, in the regression. To capture possible non-linearity in the $\mathrm{DD}$ effect, the product of volatility with a discrete version of DD is added to the regression. Specifically, we add the product $V_{i t} D D_{i t}^{S}$ for $s=1, \ldots, 4$, where $D D_{i t}^{S}$ is defined as before.

It is well known that aggregate stocks and bonds are driven by common factors (Fama and French, 1989; Shiller and Beltratti, 1992; Campbell and Ammer, 1993). We control for common market conditions using the VIX index, which is a widely used measure of the implied volatility of the S\&P 500 Index options. ${ }^{1}$ The VIX has been considered an important indicator of market expectations, investor sentiment, and market volatility (Whaley, 2000, 2008). Because it is directly related to the market values of calls and puts, the VIX reflects what the option traders think of future market volatility. This forward-looking nature of the VIX makes it a particularly powerful state variable. The importance of this control lies in the potential role of common shocks to real cash flow, market risk and investor sentiment in the time variation in stock-bond co-movement.

\footnotetext{
${ }^{1}$ We thank the referee for drawing our attention to this important point.
} 
As pointed out by Baker and Wurgler (2012), common factors help separate firm-level correlation from aggregate correlation.

At the aggregate level, the dominant argument is flight-to-quality. Kim, Moshirian, and Wu (2006) and Connolly, Stivers, and Sun (2007) find that market uncertainty reduces the stock-bond correlation. Some authors argue that the cash flow effect is more important during contractions, leading to lower or negative stock-bond correlations during recessions. In contrast, during expansions the discount rate is more important, thus leading to positively correlated stock and bond returns during such periods (Ilmanen, 2003; Boyd, Jagannathan, and Hu, 2005; Andersen et al., 2007). However, d'Addona and Kind (2006), in their study of the G7 countries, find evidence that only inflation uncertainty reduces stock-bond correlation, whereas real interest rate uncertainty actually increases the correlation. Moreover, for small capitalization stocks, Jensen and Mercer (2003) find evidence that the stock-bond correlation is lower (rather than higher) during an expansion than during a contraction. Thus, the empirical evidence is not conclusively in favor of the flight-to-quality argument.

Although aggregate risk (VIX) can influence the general level of stock-bond correlation, it may also have different effects for different firms. Bhamra, Kuehn, and Strebulaev (2010) propose a model whereby both stocks and bonds are sensitive to aggregate consumption and the firm's earnings, and find a positive relation between consumption growth and firms' earnings growth. This implies that the VIX might moderate the impact of firm risk. We thus account for this potential moderating effect by including an interaction between aggregate risk and firm risk (asset volatility and DD). Overall, the full regression is expressed as follows:

$$
\begin{aligned}
C_{i t}= & \alpha_{\mathrm{t}}+\alpha_{1} D D_{i t}+\alpha_{2} D D_{i t}^{2}+\sum_{s=1}^{4} \gamma_{s} D D_{i t}^{s}+\alpha_{3} V_{i t}+\alpha_{4} V_{i t}^{2}+\alpha_{5} V_{i t} D D_{i t}+ \\
& \sum_{s=1}^{4} \delta_{s} V_{i t} D D_{i t}^{s}+\alpha_{6} V I X_{i t}+\alpha_{7} V I X_{i t} D D_{i t}+\alpha_{8} V I X_{i t} V_{i t}+\varepsilon_{i t} .
\end{aligned}
$$


As emphasized by Petersen (2009), the OLS standard errors in equation (13) may be biased and underestimate the true variability in the estimated coefficients due to the correlation of the residuals across time for a given firm (time series dependence) and/or across different firms (cross-sectional dependence). The standard errors are corrected to account for the time series dependence, while the cross-sectional dependence is addressed by adding dummy variables. This approach takes into account potential error correlation across both dimensions. An alternative way to correct for errors across both dimensions is to correct them for the cross-sectional dependence and add firm dummies to address the time series dependence. However, the firm dummies partially capture the effect of credit risk on the correlation, which is a main point of interest of this paper, and thus the use of a model with period dummies is preferred. Further, the period dummy variables fully capture common time variations in the correlation, which makes them an alternative to common variables such as VIX.

\subsection{Data}

Following Scruggs and Glabadanidis (2003), the correlation is estimated at the monthly level as noise in the returns at higher frequencies makes it difficult to determine the true relation between the returns. We use firm-level equity and bond data. Since bond data are relatively scarce compared to equity data, we start our sample selection with all straight corporate bonds issued by nonfinancial companies in the U.S. market available in the Thompsons Reuters Datastream database. When multiple bonds are available from the same issuer, the bond with the maximum number of observations is used. This is preferred to averaging the data of different bonds with a common issuer as bonds have different characteristics, such as duration and issue size. Bonds with less than 
36 monthly observations, asset-backed bonds, bonds with any sort of collateral, or with an average market value of less than $\$ 10$ million are excluded from the sample. Once the bond data are collected, they are matched with the equity data, also obtained from the Datastream database. The matched sample consists of 351 firms and 33,870 firm-month observations.

All other variables (distance to default, equity volatility, firm asset value, bond duration, and bond issue value) are estimated at the daily level and then converted into monthly series by averaging daily observations. The accounting data required for the estimation of DD are obtained from Compustat, and the risk-free interest rate data are obtained from the Datastream database. Finally, daily VIX Index data are obtained from the Chicago Board Options Exchange. The descriptive statistics for the variables used in the empirical model are presented in Table 1, while the time series of cross-sectional average equity and bond returns are shown in Figure 1.

[Insert Table 1 about here]

[Insert Figure 1 about here]

The sample covers the period from August 1996 to February 2011. Not all series cover the entire sample period, so our panel is unbalanced. It should be noted that the number of observations available at the beginning of the sample period (1996-2000) is much lower than that later in the sample period (2001-2011). However, the earlier dataset is still large (1,519 observations for 33 firms) compared to other studies dealing with bond data.

\section{Results}

\subsection{The conditional correlation between equity and bond returns}

The conditional correlation between equity and bond returns is estimated initially by means of both symmetric and asymmetric bivariate diagonal VECH/diagonal BEKK models, as described 
in Bollerslev, Engle, and Wooldridge (1988). Following Scruggs and Glabadanidis (2003), the correlation is estimated at the monthly level, as noise in the returns at higher frequencies makes it difficult to determine the true relation between the returns. The statistical characteristics of the estimated correlations are similar across both types of model, except for a slight increase in skewness in the asymmetric model. We find no clear evidence that the asymmetric model performs better. For example, while the AIC favors the asymmetric model $53 \%$ of the time, the Schwartz criterion indicates that the symmetrical model is preferred in $66 \%$ of cases. We therefore use the EBR correlation estimated by the symmetric version of the diagonal VECH model as a proxy for the unobserved correlation. The descriptive statistics of the correlation series are presented in Table 2, while the cross-sectional averages of the series are shown in Figure 2.

[Insert Table 2 about here]

[Insert Figure 2 about here]

The mean of both correlation series is around 0.089 , which provides support for Hypothesis 1 (EBR correlation is positive on average). The two models used in estimating the conditional correlations give virtually identical means, as shown in Table 2. Hypothesis 1 is also confirmed by the results of an autoregressive model presented in Table 3. As expected, these conditional correlations are highly correlated but stationary. The long-run correlation implied by this autoregressive model is $0.089(=0.028 /[1-0.403-0.284])$ for the symmetric model, which is virtually identical to that for the sample mean.

[Insert Table 3 about here] 
The remaining three hypotheses, $\mathrm{H} 2$ to $\mathrm{H} 4$, are addressed by the full model. We estimate both the Period Fixed Effects Model and the Constant Coefficient Model (i.e., the model without effects). As noted above, the standard errors may be correlated cross-sectionally and/or serially. The standard errors shown in Table 4 are corrected for serial correlation, while the potential crosssectional correlation is addressed by adding period dummies (Period Fixed Effects Model) or the VIX Index (Constant Coefficient Model). The period fixed effects and VIX Index capture common effects affecting all firms. Consequently, the fixed effects and VIX cannot be included in the model simultaneously because of perfect multicollinearity. Therefore, the VIX Index is omitted from the Period Effects Model and included only in the Constant Coefficient Model. A higher explanatory power and a lower AIC value of the Period Effects Model imply that the period dummies outperform VIX in capturing systematic effects. The probabilities from the uncorrected standard errors are also shown and confirm that the uncorrected standard errors are generally less conservative. This approach to addressing two sources of error correlation is suggested by Petersen (2009).

[Insert Table 4 about here]

Before proceeding with the analysis, we conducted formal redundancy tests of the fixed and random effects. The chi-square statistic for the redundancy of the fixed effects (Baltagi, 2005, pp. 34-35) is 1,647.93 with 174 degrees of freedom. This statistic is highly significant and rejects the null that the fixed effects are redundant. On the other hand, the chi-square statistic for the validity of the random effects model (Hausman, 1978) is also very high at 723.35 with 15 degrees of freedom, which is also highly significant and thus rejects the null that the effects are random. 


\subsection{The relation between credit risk and the EBR correlation}

The structural model implies that the strength of the EBR correlation depends on the level of credit risk. High-quality firms are very unlikely to default, so new information from equity markets has limited importance for the debt holders of such firms. Therefore, the returns on high-quality bonds behave like those of government bonds. However, a change in the value of equity becomes increasingly relevant for bond pricing as the level of credit risk increases. When a firm is on the brink of bankruptcy, bond returns are expected to be highly and positively correlated with equity returns. The level of credit risk is proxied by the DD of Merton (1974). A higher DD implies lower credit risk. Therefore, it is expected that DD has a negative impact on the correlation between equity and bond returns.

The results presented in Table 4 appear to provide some support for Hypothesis 2. The impact of credit risk on the correlation is captured by the continuous DD measure and a set of dummy variables, which take the value of one depending on the distance value. As expected, the coefficients of the dummy variables decrease monotonically as firms move further away from the default point. All four dummy variables are highly significant. This result indicates that the correlation diminishes as credit quality improves. The coefficient of the continuous distance variable is negative, implying decreasing correlation as firm credit quality increases. However, this coefficient is not significant when we correct for serial correlation. The quadratic term is clearly insignificant, suggesting that non-linearity takes a discrete form only.

\subsection{The relation between equity volatility and EBR correlation}

As mentioned previously, the effect of equity volatility on the correlation that we might expect is not obvious. The structural model predicts a negative relation since equity holders (as holders 
of a call option on the firm's assets) stand to benefit from the upside potential associated with higher volatility, whereas debt holders face only a higher default probability caused by an increase in volatility. On the other hand, a stronger correlation is associated with a higher credit risk. Since volatility has a positive impact on credit risk, the relation between equity volatility and the correlation may be positive. In order to understand the role of equity volatility, it is therefore essential to control for the level of credit risk.

As can be seen from Table 4, the equity volatility and squared volatility coefficients are statistically significant and their size and sign implies a hump-shaped effect. Ignoring the interaction of volatility with other risk factors, the coefficients imply that volatility has a positive impact (given the volatility values in our sample), which diminishes as volatility increases. However, the coefficients of equity volatility and the DD interaction variables are all negative. This implies that the equity volatility impact lowers as the credit quality of firms improves. This result highlights the importance of carefully controlling for credit risk in the analysis of the relation between equity volatility and the EBR correlation. This may also explain why Scheicher (2009) finds that equity volatility has a negative impact on the correlation between equity returns and CDS premia (implying a positive impact on equity and bond returns correlation). His use of a simple leverage ratio to control for credit risk may have affected his empirical conclusions.

\subsection{The interaction between equity volatility and credit risk in explaining EBR correlation}

The structural model implies that the importance of equity volatility, as a determinant of the value of corporate debt, increases with credit risk. Campbell and Taksler (2003) and Cremers et al. (2008) show that the economic and the statistical significance of equity volatility in determining the credit spread increases as the DD shrinks (i.e. credit risk increases). 
The next part of Table 4 shows this effect through the interaction between volatility and the distance to default. The continuous interaction variable and all four dummy interaction variables are significant and have negative coefficients, implying that the equity volatility effect decreases as firms' credit quality improves.

\subsection{The predicted correlation}

The results of Table 4 are not easy to interpret as the regressions involve many interaction terms. To help visualize the combined effect of changes in equity volatility and the DD on the correlation, we use the coefficients in Table 4 to estimate the correlations for the values of equity volatility from $1 \%$ to $70 \%$ and the DD from zero to seven in the three market regimes as characterized by the minimum, average and maximum value of the VIX Index.

The results in Table 5 show that the average correlation for the values of equity volatility of $1 \%$ to $70 \%$ monotonically decreases as firms move away from the default point. Starting with the value of $71 \%$ for firms on the brink of bankruptcy, the average correlation monotonically decreases to $5 \%$ in the Period Fixed Effects Model and $-8 \%$ in the Constant Coefficient Model as DD increases. This is consistent with Hypothesis 2.

[Insert Table 5 about here]

Holding DD constant, we examine how an increase in equity volatility from $1 \%$ to $70 \%$ impacts the correlation. As shown in Table 5, the coefficients for both models generally imply that an increase in equity volatility lowers the correlation. The volatility impact, which we define as a change in the correlation as equity volatility increases from $1 \%$ to $70 \%$, is just $1.5 \%$ in the Period 
Fixed Effect Model (-8.3\% in the Constant Coefficient Model) for the riskiest firms and $-47 \%$ for the safest firms in both models. This is consistent with Hypothesis 3, which states that equity volatility has a negative impact on the correlation, but provides little support for Hypothesis 4, which states that the economic impact of equity volatility on the correlation increases as DD falls.

It should be noted that this result is derived under the assumption that equity volatility increases while DD remains constant. Since DD and equity volatility are correlated, the distance to default can only remain constant if its other determinants, mainly leverage, change. In other words, an increase in equity volatility from $1 \%$ to $70 \%$ will lower the DD for most firms. This effect is stronger for riskier firms. Bearing in mind this limitation, the volatility impact analysis shows a positive impact of a change in equity volatility on the EBR correlation, which is similar to the impact reported by earlier studies (e.g., Campbell and Taksler, 2003).

Finally, we examine whether the relation between the firm-level risk factors and the correlation is the same in different market regimes. As mentioned before, in the Period Fixed Effects Models, we control for the common effects with the period effects (i.e., 174 dummy variables) while in the Constant Coefficient Model, we use the VIX Index instead of the period effects. Further, we use controls for the interaction between VIX and firm-level risk factors in both models (i.e., equity volatility and DD). As illustrated in Figure 3, the relation described above between the EBR correlation and firm-level risk factors holds for the minimum VIX regime (i.e., VIX $=10.8$, the sample minimum) and the average VIX regime (i.e., VIX=22.4, the sample mean). However, the relation breaks down for the maximum VIX regime (i.e., VIX $=62.6$, the sample maximum).

[Insert Figure 3 about here] 
In the maximum VIX regime, the relation between the correlation and the firm-level risk factors is essentially flat. Both models consistently predict a flat relation but provide different values for the level of the correlation, with the Period Fixed Effects Model predicting a higher expected correlation relative to the Constant Coefficient Model. The difference in the predicted level of the EBR correlation can be ascribed to the difference in the power of the period effects and the VIX in capturing the common effects.

The models' adjusted R-squared and AIC suggest that the period effects (i.e., 174 dummy variables) outperform the VIX Index in capturing the common effects. Therefore, an unexpected low correlation in the maximum VIX regime can be attributed to weaknesses of VIX in capturing the common effects. However, both models consistently imply a flat relation between the correlation and the firm-level factors in the maximum VIX regime.

Figure 4 illustrates the time behavior of monthly EBR correlation, annualized equity volatility, and DD over the cycle for the lowest DD (risky) firm and the highest average DD (safe) firm in our sample. These two extreme examples might help further illuminate the interaction of firmlevel (DD and equity volatility) and aggregate (VIX) influences on EBR correlation. On average, the risky (safe) firm's EBR correlation is $73 \%(1 \%)$, annualized equity volatility is $71 \%(18 \%)$, and DD is $1.4(15.6)$.

Consistent with our results, Figure 4 clearly shows that the EBR correlation of the risky firm is consistently stronger than the correlation of the safe firm. Both equity risk and credit risk are positively associated with aggregate risk (VIX), but the association is stronger between equity volatility and VIX.

Despite the strong link between the firm level and aggregate factors, their influence on the EBR correlation of the two firms is quite distinct. For the safe firm, the correlation is low (mostly under 
0.10) and even negative for low VIX and equity volatility. However, although the safe firm's EBR correlation increases during periods of turmoil, it never exceeds $20 \%$. The story is quite different from the lowest average DD firm. The EBR correlation is generally very high (mostly around 0.80). Interestingly, EBR correlation appears negatively related to both equity volatility and VIX, although the EBR correlation level remains above 0.60 in most cases.

When the VIX peaked at the end of 2008, the safe firm's EBR correlation increased to around 0.20, while the risky firm's EBR correlation decreased (to around 0.25) despite the increase in its equity and credit risks. Consequently, the difference between the two EBR correlations almost vanished. This is also in line with our result that the common factor is a major determinant of EBR correlation when the market risk is elevated.

Although we cannot generalize the two EBR correlation patterns to other firms, these two extreme examples serve to demonstrate that the combined influence of firm-specific and aggregate factors is dependent on the risk profile of the firm in question.

[Insert Figure 4 about here]

\section{Robustness checks}

\subsection{The correlation between equity and bond returns modeled as an asymmetric diagonal VECH} process

To examine whether the results of Table 4 are influenced by the choice of method for estimating the conditional correlation between equity and bond returns, we estimate bond and equity return correlation using an asymmetric bivariate diagonal VECH $(1,1)$ model. The basic model for Table 4 (equation 13) is then re-estimated. The results are summarized in Panel A of Table 6. 
[Insert Table 6 about here]

The variables in the re-estimated model retain the same level of statistical significance and the parameter estimates have nearly identical values. Consequently, the empirical correlations (unreported for the sake of space) implied by the asymmetric model are nearly identical. Thus, changing the process generating the EBR correlation does not change our conclusions in the preceding section. Our results are therefore robust to the method used to estimate the EBR correlation.

\subsection{Estimating equity volatility as a simple moving average instead of a $\operatorname{GARCH}(1,1)$ process}

To examine whether the empirical results presented in Table 4 are influenced by the equity volatility estimation method, we estimated equity volatility as the volatility of returns in excess of the return on the S\&P 500 Index. The equity volatility for a month is estimated as the standard deviation of excess daily returns within a month, which is then annualized. As shown in Figure 5, the $\operatorname{GARCH}(1,1)$ and the moving average equity volatility series are highly correlated $(\rho=85 \%)$, which explains the similarity between the results based on the GARCH volatility (Table 4) and the results based on the moving average volatility shown in Panel B of Table 6. However, the GARCH estimates are generally higher than the moving average estimates and the difference is largest in 2008 during the financial crisis. It is thus not surprising to see the estimates based on the moving average volatility having lower magnitude than those based on the GARCH volatilities. Nevertheless, all coefficients retain their sign and most retain their significance. One notable exception is the quadratic terms of DD and equity volatility, which have swapped their significance. The empirical correlations (available upon request) based on the moving average 
equity volatility have a very similar pattern, although they are marginally lower than those seen in Figure 3 and Table 5.

\section{[Insert Figure 5 about here]}

\subsection{Firm size and bond characteristics}

Firm size, bond duration, and bond issue size are important characteristics that can potentially influence EBR correlation. Credit risk exposure may be related to firm size. Likewise, bond duration and bond issue size are important characteristics that can potentially influence the EBR correlation. The relation between the duration and the risk inherent in a bond is straightforward: a longer duration indicates higher risk, ceteris paribus. Therefore, the returns on long-term bonds should behave more like equity returns than the returns on short-term bonds. The size of a bond issue may affect the EBR correlation through the liquidity mechanism. Large bond issues are more liquid, and therefore their values should react more quickly to shocks in the value of the issuing firm's equity.

To examine whether our results are sensitive to changes in firm size, as well as the maturity and liquidity of bonds in the sample, the models are augmented with three sets of dummy variables to control for firm size, bond duration, and issue size. The largest firms, the largest issue size, and the longest duration are the benchmarks for which we have no dummies in order to avoid the dummy variable trap. In each case, the number of dummies and their associated thresholds were selected using the approach detailed in Appendix 1. The results for the extended model are presented in Table 7.

[Insert Table 7 about here] 
We find that controlling for firm size, bond issue size, and duration does not alter the effect (and the interaction) of credit risk and equity volatility on EBR correlation. In Table 4, the coefficients of all variables in the unextended model retain their statistical significance, magnitude, and sign, while the coefficients of the vast majority of the 17 added variables are highly insignificant. The only variables significant at the 5\% level are the dummy capturing bonds with the shortest maturity, and one of the asset value dummies. The negative coefficient here leads to the sensible implication that the EBR correlation is negatively related to bond duration. More specifically, the returns on bonds with durations of less than 3.7 years have correlations that are lower than those for longer duration bonds by 6.03 percentage points. The asset value and bond value are unrelated to the correlation. One possible exception is that the median value firm (log asset value between 8 and 9) might have a correlation that is lower (by 7.4 percentage points) than either bigger or small firms. However, we should not read too much into this result as it may simply be the result of data mining or Type I error.

\section{Discussion and conclusions}

We examine how changes in firm-level risk factors and the systematic risk impact the correlation between equity and bond returns. Unlike most of the empirical studies that examine aggregate data, this study is based on a sample consisting of 351 firms and over 33,000 monthly observations at the firm level.

The theoretical framework for analysis of EBR correlation is laid down by Merton (1974). He shows that the values of both equity and debt depend primarily on the value and the volatility of the underlying firm's assets. Factors affecting the value of the assets push the values of equity and bonds in the same direction and therefore induce a positive correlation between the returns of these 
two asset classes. On the other hand, an increase in the volatility of a firm's assets augments the value of equity and depresses the value of debt, which clearly induces a negative correlation between the returns from these two asset classes.

In line with existing empirical evidence, we find that, on average, bond and equity returns are positively correlated. This implies that the prices of securities are in general driven by changes in the value of underlying firm assets rather than by any management actions causing a wealth transfer between stock and debt holders.

Credit risk is found to be a major determinant of the correlation. The returns of equity and debt securities become more correlated as firms approach the default point. After controlling for credit risk, we find that equity volatility has a negative effect on the correlation. This is in line with the structural model, which predicts that a change in equity volatility has an opposing effect on the values of equity and debt, but it contrasts to Scheicher (2009), who finds that the relation between equity volatility and the EBR correlation is positive, although his result is probably caused by weak control for the level of credit risk, which allows equity volatility to capture the credit risk effect. An increase in equity volatility has a negative impact on the EBR correlation, and the magnitude increases as firm credit quality improves. This implies that an increase in the equity volatility of high-credit quality firms benefits equity holders and hurts bondholders.

The abovementioned relation between the firm-level risk factors and the EBR correlation weakens as market risk increases. When market risk, as measured by the VIX Index, is highest, the predicted impact of credit risk and equity volatility on EBR correlation is essentially flat. The correlation is positive and high but it seems to be driven by market-wide risk factors rather than firm-level risk factors. 
Whereas the potential diversification benefits of bonds are well recognized, researchers have focused on evaluating bonds and stocks that are not necessarily from the same firm. Because they share claims on the same firm's assets, the bonds and stocks of the same firm have different diversification opportunities from the bonds and stocks of different firms. Thus, investors who seek to benefit from the within-firm diversification opportunities might find our results of interest.

Generally, investment strategies based on predictions of the structural model and hedging strategies involving firm-level risk factors will be less effective as the market risk increases. The EBR correlation of a high credit quality firm, for example, is typically low so its equity and debt behave as distinct asset classes. Further, an increase in this firm's equity volatility supports the equity value while depressing the debt value. As the market risk increases, the EBR correlation strengthens, so investors with long positions in both asset classes will see their portfolios less diversified.

Our findings have implications for volatility and index investing strategies, as well as the fine tuning of weight in portfolios consisting of equities and corporate bonds. Volatility strategies, which have gained popularity over the past decade, can provide effective diversification because of the difference in asset cash flows relative to the asset's price movements. One potential implication of our findings, therefore, relates to firm-level volatility-based investment strategies. However, firm-level volatility strategies will not yield diversification benefits during market turmoil, because a high market risk flattens the relation between EBR correlation and other firmlevel volatility.

Similarly, our results are relevant to index investing. This type of investment typically focuses on a single asset class and is generally passive. Our results show that each stock index constituent has a matching investment opportunity that can have low or even negative correlation. Thus, even 
passively, index investors have a sub-optimal portfolio because they ignore the potential diversification benefits of bonds. More importantly, EBR correlations are time varying, which implies that investment opportunities are also time varying. Nevertheless, whether the risk-return benefits will justify greater management fees and expenses remains an empirical question.

Our results are also of interest to investors who are interested in varying their portfolio weights based on more accurate correlation estimates. Because the EBR correlation between a stock and a bond of the same firm is a function of both firm-specific and aggregate predictors, we contend that correlation estimates will be more accurate. The benefits of such accuracy materialize during times of extreme market volatility where the benefits from diversification are most needed. Therefore, using accurate correlation estimates is crucial for those who do not wish to see the benefits of diversification being eroded by poor correlation estimates when such diversifications are needed most.

Finally, investors need to understand the implications of the time variation in the stock-bond relation and its sensitivity to macroeconomic factors (in the case of aggregate correlation) and firm asset volatility and risk (in the case of correlation at the firm level). Applications that rely on unconditional estimates of the stock-bond correlation can thus be misleading because they ignore potential shifts in the factors that drive conditional EBR correlations. A firm's risk characteristics will change over time, and investors should therefore consider the change in the stock-bond correlation and its potential consequences for portfolio rebalancing. 


\section{References}

Alexander, G. J., Edwards, A. K., and Ferri, M. G. (2000). 'What does Nasdaq's high-yield bond market reveal about bondholder-stockholder conflicts'. Financial Management, Vol. 29, No. 1, 23-39.

Andersen, T.G., Bollerslev, T., Diebold, F.X. and Vega, C. (2007). 'Real-time price discovery in stock, bond and foreign exchange markets'. Journal of International Economics, Vol. 73, No. 2, 251-277.

Ang, A. and Chen, J. (2002), 'Asymmetric Correlations of Equity Portfolios', Journal of Financial Economics, Vol. 63, No. 3, pp. 443-494.

Baele, L., Bekaert, G. and Inghelbrecht, K. (2010), 'The Determinants of Stock and Bond Return Comovements' The Review of Asset Financial Studies, Vol. 23, No. 6, pp. 2374-2428.

Baker, M. and Wurgler, J. (2012), 'Comovement and Predictability Relationships Between Bonds and the Cross-section of Stocks' The Review of Asset Pricing Studies, Vol. 2, No. 1, pp. 57-87.

Baltagi, B. H. (2005). Econometric Analysis of Panel Data, Third Edition (West Sussex, England: John Wiley \& Sons).

Bekaert, G. and Wu, G. (2000), 'Asymmetric Volatility and Risk in Equity Markets', The Review of Financial Studies, Vol. 13, No. 1, pp. 1-42.

Belke, A. and Gokus, C. (2011), 'Volatility Patterns of CDS, Bond and Stock Markets Before and During the Financial Crisis: Evidence From Major Financial Institutions', Working Paper (German Institute for Economic Research, Berlin).

Bhamra, H.S., Kuehn L.A. and Strebulaev, I.A. (2010). 'The Levered Equity Risk Premium and Credit Spreads: A Unified Framework', Review of Financial Studies, Vol. 23, No. 2., pp. 645-703.

Bhanot, K., Mansi, S. and Wald, J. (2010), 'Takeover Risk and the Correlation Between Stocks and Bonds', Journal of Empirical Finance, Vol. 17, No. 3, pp. 381-393. 
Black, F. and Scholes, M. (1973), 'The Pricing of Options and Corporate Liabilities', The Journal of Political Economy, Vol. 81, No. 3, pp. 637-654.

Bollerslev, T. (1986), 'Generalized Autoregressive Conditional Heteroskedasticity', Journal of Econometrics, Vol. 31, No. 3, pp. 307-327.

Bollerslev, T., Engle, R. and Wooldridge, J. (1988), 'A Capital Asset Pricing Model with TimeVarying Covariances', Journal of Political Economy, Vol. 96, No. 1, pp. 116-131.

Boyd, J. H., Jagannathan, R. and Hu, J. (2005), 'The stock market's reaction to unemployment news: Why bad news is usually good for stocks', Journal of Finance, Vol. 60, No. 2, pp. 649-672.

Campbell, J. Y., and Ammer, J. (1993), 'What Moves the Stock and Bond Markets? A Variance Decomposition for Long-term Asset Returns', The Journal of Finance, Vol. 48, pp.3-37.

Campbell, J.Y. and Taksler, G. (2003), 'Equity Volatility and Corporate Bond Yields', The Journal of Finance, Vol. 58, No. 6, pp. 2321-2350.

Campbell, J. Y., Hilscher, J. and Szilagyi, J. (2008), 'In Search of Distress Risk', The Journal of Finance, Vol. 63, No. 6, pp. 2899-2939.

Cheyette, O. and Tomaich, T. (2003), 'Empirical Credit Risk', Barra Fixed Income Research Working Paper (Barra, Inc.).

Connolly, R., Stivers, C. and Sun, L. (2005), 'Stock Market Uncertainty and the Stock-Bond Return Relation', Journal of Financial and Quantitative Analysis, Vol. 40, No.1, pp.161194.

Connolly, R., Stivers, C. and Sun, L. (2007), 'Commonality in the time variation of stock-bond and stock-stock return comovements', Journal of Financial Markets, Vol. 10, No. 2, pp. 192-218.

Cremers, M., Driessen, J., Maenhout, P. and Weinbaum, D. (2008), 'Individual Stock-Option Prices and Credit Spreads', Journal of Banking \& Finance, Vol. 32, No. 12, pp. 2706-2715.

d'Addona, S. and Kind, A.H. (2006), 'International stock-bond correlations in a simple affine asset pricing model', Journal of Banking \& Finance, Vol. 30, No. 10, pp. 2747-2765. 
Ding, Z. and Engle, R. (2001), 'Large Scale Conditional Covariance Matrix Modeling, Estimation and Testing', Journal of Empirical Finance, Vol. 1, No. 1, pp. 83-106.

Engle, R. and Kroner, K. (1995), 'Multivariate Simultaneous Generalized ARCH', Econometric Theory, Vol. 11, No. 1, pp. 122-150.

Fama, E. F., and French, K. R. (1989), 'Business Conditions and Expected Returns on Bonds and Stocks', Journal of Financial Economics, Vol. 25, No. 1, pp. 23-49.

Gigerenzer, G. and Goldstein, D.G. (1996), 'Reasoning the Fast and Frugal Way: Models of Bounded Rationality', Psychological Review, Vol. 103, No. 4, pp. 650-669.

Gulko, L. (2002), 'Decoupling', Journal of Portfolio Management, Vol. 28, No. 3, pp. 50-58.

Hansen, B. E. (2000), 'Sample Splitting and Threshold Estimation', Econometrica, Vol. 68, No. 3, pp. 575-603.

Hausman, J. A. (1978). 'Specification Tests in Econometrics', Econometrica, 46, 1251-1272.

Hillegeist, S. A., Keating, E. K., Cram, D. P., and Lundstedt, K. G. (2004), 'Assessing the Probability of Bankruptcy', Review of Accounting Studies, Vol. 9, No. 1, pp. 5-34.

Hotchkiss, E. and Ronen, T. (2002), 'The Informational Efficiency of the Corporate Bond Market: An Intraday Analysis', The Review of Financial Studies, Vol. 15, No. 5, pp. 1325-1354.

Ilmanen, A. (2003), 'Stock-bond correlations', Journal of Fixed Income, Vol. 13, No. 2, 55-66.

Jensen, G. R., Mercer, J.M. (2003), ‘New evidence on optimal asset allocation', Financial Review, Vol. 38, No. 3, pp. 435-454.

Kim, S., Moshirian, F. and Wu, E. (2006), 'Evolution of international stock and bond market integration: Influence of the European Monetary Union', Journal of Banking \& Finance, Vol. 30, No. 5, pp. 1507-1534.

Kwan, S. (1996), 'Firm-Specific Information and the Correlation between Individual Stocks and Bonds', Journal of Financial Economics, Vol. 40, No. 1, pp. 63-80.

Maxwell, W. and Stephens, C. (2003), 'The Wealth Effects of Repurchases on Bondholders', The Journal of Finance, Vol. 58, No. 2, pp. 895-919. 
Merton, R. (1974), 'On the Pricing of Corporate Debt: The Risk Structure of Interest Rates', The Journal of Finance, Vol. 29, No. 2, pp. 449-470.

Norden, L. and Weber, M. (2009), 'The Co-Movement of Credit Default Swap, Bond and Stock Markets: An Empirical Analysis', European Financial Management, Vol. 15, No. 3, pp. 529-562.

Petersen, M. (2009), 'Estimating Standard Errors in Finance Panel Data Sets: Comparing Approaches', The Review of Financial Studies, Vol. 22, No. 1, pp. 435-480.

Ronn, E. I., and Verma, A. K. (1986), 'Pricing Risk-Adjusted Deposit Insurance: An Option-Based Model, The Journal of Finance, Vol. 41, No. 4, pp. 871-895.

Scheicher, M. (2009). 'The Correlation of a Firm's Credit Spread With its Stock Price: Evidence From Credit Default Swaps'. in G. N. Gregoriou (ed.), Stock Market Volatility (Chapman \& Hall/CRC Finance, London), pp. 405-419.

Scruggs, J. and Glabadanidis, P. (2003), 'Risk Premia and the Dynamic Covariance Between Stock and Bond Returns', The Journal of Financial \& Quantitative Analysis, Vol. 38, No. 2, pp. 295-316.

Shiller, R. J., and Beltratti, A. E. (1992), 'Stock Prices and Bond Yields: Can Their Comovements Be Explained in Terms of Present Value Models?', Journal of Monetary Economics, Vol. 30, pp. $25-46$.

Whaley, R.E. (2000), 'The Investor Fear Gauge', The Journal of Portfolio Management, Vol. 26, No. 3, pp. 12-17.

Whaley, R. E. (2008), Understanding VIX. Available at SSRN: http://dx.doi.org/10.2139/ssrn.1296743. 


\section{Appendix}

The threshold values for the dummy variables are determined in the spirit of Hansen (2000). We basically fit all potential combinations of models using predetermined threshold increments and select the optimal model based on the Akaike information criterion (AIC).

We assign $D_{i t}^{\mathrm{k}}=I\left(\tau_{\mathrm{k}-1} \leq X_{i t}<\tau_{\mathrm{k}}\right)$ as the dummy variables, where $X_{i t}$ is the value of a variable for firm $i$ at time $t, \tau_{\mathrm{k}}$ are thresholds, and $I($.$) is the indicator function. \tau_{0}$ is equal to the variable's sample minimum, the first threshold, $\tau_{1}$, is equal to the lower limit $K_{\mathrm{L}}$, and the last threshold, $\tau_{\mathrm{n}}$, is equal to the upper limit $K_{\mathrm{U}}$. The difference between the lower and upper limits covers the large majority of observations. The first threshold, $\tau_{1}$, increases by an increment of 0.1 , and the difference between two thresholds, $s$, starts at 0.5 and increases by an increment of 0.5 , i.e. $\delta=0.5,1.0,1.5, \ldots$. The threshold selection procedure involves estimation of models with all possible combinations of the number or thresholds $(n)$, the starting value of $\tau_{1}$, and the differences between two thresholds $(\delta)$, which covers the range from $K_{\mathrm{L}}$ to $K_{\mathrm{U}}$.

In the case of one threshold, the procedure simplifies to estimating the models with one dummy variable $D_{i t}^{1}=I\left(X_{i t}<\tau_{1}\right)$ with $\tau_{1}=K_{\mathrm{L}}, K_{\mathrm{L}}+0.1, K_{\mathrm{L}}+0.2, \ldots, K_{\mathrm{U}}$.

In the case of two thresholds, $D_{i t}^{1}=I\left(X_{i t}<\tau_{1}\right)$ and $D_{i t}^{2}=I\left(\tau_{1} \leq X_{i t}<\tau_{2}\right)$, where $\tau_{1}=$ $K_{\mathrm{L}}, K_{\mathrm{L}}+0.1, K_{\mathrm{L}}+0.2, \ldots, K_{\mathrm{U}}-\delta$, and $\tau_{2}=\tau_{1}+\delta$

In the case of $n$ thresholds, $D_{i t}^{1}=I\left(X_{i t}<\tau_{1}\right)$ and $D_{i t}^{\mathrm{k}}=I\left(\tau_{\mathrm{k}-1} \leq X_{i t}<\tau_{\mathrm{k}}\right)$, where $\tau_{1}=$ $K_{\mathrm{L}}, K_{\mathrm{L}}+0.1, K_{\mathrm{L}}+0.2, \ldots, K_{\mathrm{U}}-(\mathrm{n}-1) \delta$, and $\tau_{\mathrm{k}}=\tau_{1}+(\mathrm{k}-1) \delta$

\section{The distance to default thresholds}

We perform the procedure described above, and estimate models with all combinations of the number of dummies ( 1 to 26 ), the starting value of $\tau_{1}=0.5$, and the differences between two 
thresholds $\delta=0.5,1,1.5 \ldots$, which cover the range from $K_{\mathrm{L}}=0.5$ to $K_{\mathrm{U}}=13$. The values between these limits cover $98 \%$ of the observations.

We estimate 4,753 models and examine their AIC and sum of squared errors (SSE). The lowest AIC gives a model with 15 dummy variables or thresholds, and the lowest SSE gives a model with 26 dummy variables. The greatest improvement in AIC (94\%) and SSE (90\%) is achieved by the best performing model with four dummies. Therefore, we use the best performing four-dummy model in order to present a model that is as parsimonious as possible. Thus, the optimal thresholds for the distance to default dummies are $0.8,1.8,2.8$, and 3.8 .

\section{The robustness variable thresholds}

For the robustness check, we augmented the model depicted in equation (13) (with four DD dummies) with dummy variables for firm asset value, bond issue value and bond time to maturity.

\section{The firm asset value thresholds}

The procedure described above is performed to estimate models with all combinations of the number of dummies ( 1 to 14 ), the starting $\log$ of asset value of $\tau_{1}=5.5$, and the differences between the two thresholds $\delta=0.5,1,1.5 \ldots$, which cover the range from $K_{\mathrm{L}}=5.5$ (i.e., $\$ 245$ million) to $K_{\mathrm{U}}=12.5$ ( $\$ 268,337$ million). The values between the limits cover $99 \%$ of the observations.

We estimate 1,251 models and examine their AIC and SSE. The lowest AIC and SSE give a model with 14 dummy variables or thresholds. However, for parsimony we chose the model with six thresholds that captures $89 \%$ (88\%) of the improvement in AIC (SSE). The selected thresholds are: $6,7,8,9,10$, and 11 . 


\section{The bond issue value thresholds}

The models are estimated with all combinations of the number of dummies (1 to 10), the starting $\log$ of bond issue value of $\tau_{1}=2$, and the differences between two thresholds $\delta=0.5,1,1.5 \ldots$, which cover the range from $K_{\mathrm{L}}=2$ (i.e., $\$ 7.4$ million) to $K_{\mathrm{U}}=7$ ( $\$ 1,097$ million). The values between the limits cover $98 \%$ of the observations.

We estimate 577 models and examine their AIC and SSE. The following set of eight thresholds, which produces the lowest AIC, is selected: 3.1, 3.6, 4.1, 4.6, 5.1, 5.6, 6.1, and 6.6.

\section{The bond duration thresholds}

The models are estimated with all combinations of the number of dummies (1 to 29), the starting value of $\tau_{1}=0.5$, and the differences between the two thresholds $\delta=0.5,1,1.5 \ldots$, which cover the range from $K_{\mathrm{L}}=0.5$ to $K_{\mathrm{U}}=14.5$. The values between the limits cover $98 \%$ of the observations.

We estimate 6,126 models and examine their AIC and SSE. The lowest AIC (SSE) gives a model with 25 (28) thresholds. However, for parsimony we chose the model with three thresholds, which captures 97\% (92\%) of the improvement in the AIC (SSE). The selected thresholds are: 3.7, 7.2, and 10.7 . 


\section{Table 1}

Descriptive statistics

\begin{tabular}{lrrrrrrrr}
\hline & VIX & $\begin{array}{c}\text { Equity } \\
\text { Return }\end{array}$ & $\begin{array}{c}\text { Bond } \\
\text { Period } \\
\text { Return }\end{array}$ & $\begin{array}{c}\text { Distance to } \\
\text { Default }\end{array}$ & $\begin{array}{c}\text { Equity } \\
\text { Volatility }\end{array}$ & $\begin{array}{c}\text { Asset } \\
\text { Value }\end{array}$ & $\begin{array}{c}\text { Bond } \\
\text { Duration }\end{array}$ & $\begin{array}{c}\text { Bond Issue } \\
\text { Value }\end{array}$ \\
\hline Mean & 22.37 & 0.00 & 0.01 & 5.43 & 0.36 & $25,449.62$ & 6.91 & 238.06 \\
Median & 21.54 & 0.01 & 0.01 & 5.11 & 0.30 & $10,737.94$ & 6.33 & 184.93 \\
Maximum & 62.64 & 1.64 & 1.19 & 28.05 & 4.03 & $832,438.00$ & 18.24 & $4,567.08$ \\
Minimum & 10.82 & -1.00 & -0.75 & -2.42 & 0.09 & 66.69 & 0.00 & 2.12 \\
Std. Dev. & 8.45 & 0.11 & 0.04 & 2.73 & 0.21 & $46,157.04$ & 3.61 & 268.30 \\
Skewness & 1.73 & -0.73 & -0.03 & 0.87 & 3.38 & 5.73 & 0.19 & 5.10 \\
Kurtosis & 8.17 & 16.62 & 83.62 & 4.87 & 23.71 & 61.39 & 2.08 & 54.30 \\
Observations & 175 & 33,855 & 33,855 & 33,855 & 33,855 & 33,855 & 33,855 & 33,855 \\
\hline
\end{tabular}

Notes: Asset Value and Bond Issue Value are in USD millions. Equity and bond returns are logarithmic as specified in equations (1) and (2); the Distance to default (DD) is the difference between the market value of the assets and the book value of debt relative to the volatility of the market value of the assets; the duration is in years (equation (11)). Equity and bond returns are monthly, while other variables are calculated at the daily frequency and are converted into monthly series as the average of daily observations within the given months. 
Table 2

Descriptive statistics for the correlation series

\begin{tabular}{lll}
\hline & $\begin{array}{l}\text { Symmetric } \\
\text { DVECH }(1,1)\end{array}$ & $\begin{array}{l}\text { Asymmetric } \\
\text { DVECH }(1,1)\end{array}$ \\
\hline Mean & 0.089 & 0.088 \\
Median & 0.065 & 0.068 \\
Maximum & 1.000 & 0.991 \\
Minimum & -0.928 & -0.801 \\
Std. Dev. & 0.276 & 0.262 \\
Skewness & 0.245 & 0.382 \\
Kurtosis & 3.196 & 3.172 \\
\hline $\begin{array}{l}\text { Notes: } \text { The table provides summary statistics for equity-bond conditional } \\
\text { correlations estimated by the diagonal VECH models given in equations (4) and } \\
\text { (5). The statistics are based on 32,817 empirical correlations at the monthly level. }\end{array}$
\end{tabular}


Table 3

Test of the mean of the correlation series

\begin{tabular}{lcc}
\hline Panel A: Test of Hypothesis: Mean $=0$ & \\
\hline & $\begin{array}{c}\text { Symmetric } \\
\text { DVECH }(1,1)\end{array}$ & $\begin{array}{c}\text { Asymmetric } \\
\text { DVECH }(1,1)\end{array}$ \\
\hline Sample mean & 0.089 & 0.088 \\
Sample Std. Dev. & 0.280 & 0.260 \\
$t$-statistics & 59.620 & 61.880 \\
$p$-value & 0.000 & 0.000 \\
\hline Panel B: Correlation series autoregressive model & \\
\hline$C_{i t-1}$ & $0.403^{* * *}$ & $0.544^{* * *}$ \\
$C_{i t-2}$ & $0.284^{* * *}$ & $0.204 * * *$ \\
$C_{i t-3}$ & 0.003 & 0.021 \\
Intercept & $0.028^{* * *}$ & $0.020^{* * *}$ \\
\hline
\end{tabular}

Notes: This table provides the results of two tests of the mean of the correlation series estimated from equations (4) and (5). Panel A shows the results for a simple $t$-test on the sample mean of the two correlation series. Panel B shows the results of an autoregressive model using estimated conditional correlations:

$$
C_{i t}=\alpha_{1}+\alpha_{2} C_{i t-1}+\alpha_{3} C_{i t-2}+\alpha_{4} C_{i t-3}+\varepsilon_{i t .}
$$

*** indicates significance at the $1 \%$ level. The calculations are based on a panel of 32,817 estimated correlations. 
Table 4

Determinants of the correlation between equity and bond returns

\begin{tabular}{|c|c|c|c|c|c|c|c|}
\hline & & \multicolumn{3}{|c|}{ Panel A: Fixed Effects Model } & \multicolumn{3}{|c|}{ Panel B: Constant Coefficient Model } \\
\hline & & \multicolumn{2}{|c|}{$\begin{array}{l}\text { Corrected for Serial } \\
\text { Dependence }\end{array}$} & \multirow{2}{*}{$\begin{array}{c}\text { No } \\
\text { Correction } \\
\text { p-value }\end{array}$} & \multicolumn{2}{|c|}{$\begin{array}{l}\text { Corrected for Serial } \\
\text { Dependence }\end{array}$} & \multirow{2}{*}{$\begin{array}{c}\text { No } \\
\text { Correction } \\
\text { p-value }\end{array}$} \\
\hline & & Coefficient & p-value & & Coefficient & p-value & \\
\hline Distance to Default $\left(D D_{i t}\right)$ & $(\mathrm{H} 2)$ & -0.016 & 0.518 & 0.022 & -0.009 & 0.704 & 0.194 \\
\hline Distance to Default Squared $\left(D D_{i t}{ }^{2}\right)$ & $(\mathrm{H} 2)$ & 0.000 & 0.718 & 0.205 & 0.000 & 0.821 & 0.444 \\
\hline $\mathrm{I}(D D<0.8)$ & $(\mathrm{H} 2)$ & 0.797 & 0.000 & 0.000 & 0.863 & 0.000 & 0.000 \\
\hline $\mathrm{I}\left(0.8 \leq D D_{i t}<1.8\right)$ & $(\mathrm{H} 2)$ & 0.673 & 0.000 & 0.000 & 0.693 & 0.000 & 0.000 \\
\hline $\mathrm{I}\left(1.8 \leq D D_{i t}<2.8\right)$ & $(\mathrm{H} 2)$ & 0.480 & 0.000 & 0.000 & 0.461 & 0.000 & 0.000 \\
\hline $\mathrm{I}\left(2.8 \leq D D_{i t}<3.8\right)$ & $(\mathrm{H} 2)$ & 0.244 & 0.001 & 0.000 & 0.234 & 0.002 & 0.000 \\
\hline Equity Volatility $\left(V_{i t}\right)$ & (H3) & 1.131 & 0.001 & 0.000 & 0.855 & 0.008 & 0.000 \\
\hline Equity Volatility Squared $\left(V_{i t}^{2}\right)$ & (H4) & -0.205 & 0.000 & 0.000 & -0.230 & 0.000 & 0.000 \\
\hline Equity Volatility $\times D D_{i t}$ & (H4) & -0.269 & 0.000 & 0.000 & -0.256 & 0.000 & 0.000 \\
\hline Equity Volatility $\times \mathrm{I}\left(D D_{i t}<0.8\right)$ & (H4) & -1.069 & 0.001 & 0.000 & -1.146 & 0.001 & 0.000 \\
\hline Equity Volatility $\times \mathrm{I}\left(0.8 \leq D D_{i t}<1.8\right)$ & $(\mathrm{H} 4)$ & -0.985 & 0.000 & 0.000 & -0.989 & 0.001 & 0.000 \\
\hline Equity Volatility $\times \mathrm{I}\left(1.8 \leq D D_{i t}<2.8\right)$ & (H4) & -0.823 & 0.001 & 0.000 & -0.767 & 0.002 & 0.000 \\
\hline Equity Volatility $\times \mathrm{I}\left(2.8 \leq D D_{i t}<3.8\right)$ & $(\mathrm{H} 4)$ & -0.483 & 0.006 & 0.000 & -0.457 & 0.012 & 0.000 \\
\hline $\operatorname{VIX}\left(v_{t}\right)$ & & & & & -0.021 & 0.000 & 0.000 \\
\hline VIX x Distance to Default $\left(v_{t} D D_{i t}\right)$ & & 0.003 & 0.000 & 0.000 & 0.002 & 0.000 & 0.000 \\
\hline VIX x Equity Volatility $\left(v_{t} V_{i t}\right)$ & & 0.006 & 0.010 & 0.000 & 0.015 & 0.000 & 0.000 \\
\hline Intercept & & -0.118 & 0.382 & 0.002 & 0.353 & 0.013 & 0.000 \\
\hline
\end{tabular}

Notes: This table reports the results of tests of three hypotheses. The models are estimated using fixed period effects (VIX is dropped because of the perfect multicollinearity) and the constant coefficient (i.e., no effects), with and without correction for serial dependence. The estimated model is equation (13). The dependent variable, $\mathrm{C}_{\mathrm{it}}$, is the conditional correlation estimated from the symmetric VECH $(1,1)$ equation (4). Equity volatility, $V_{i t}$, is estimated using a GARCH $(1,1)$ model. Distance to default, $D D_{i t}$, is obtained from equation (10), and I(.) is an indicator function that equals 1 if the argument is true and zero otherwise. The selection of dummy variable sets is described in detail in the Appendix. 
Table 5

Predicted correlation between equity and bond returns

\begin{tabular}{|c|c|c|c|c|c|c|c|c|}
\hline \multirow[b]{3}{*}{ Equity Volatility } & \multicolumn{8}{|c|}{ Panel A: Correlations based on the Fixed Effects Model } \\
\hline & \multicolumn{8}{|c|}{ Distance to Default } \\
\hline & 0.01 & 1 & 2 & 3 & 4 & 5 & 6 & 7 \\
\hline 0.01 & 0.681 & 0.599 & 0.450 & 0.259 & 0.063 & 0.106 & 0.151 & 0.195 \\
\hline 0.10 & 0.696 & 0.598 & 0.439 & 0.254 & 0.077 & 0.097 & 0.117 & 0.137 \\
\hline 0.20 & 0.709 & 0.593 & 0.422 & 0.245 & 0.090 & 0.082 & 0.075 & 0.069 \\
\hline 0.30 & 0.717 & 0.583 & 0.402 & 0.232 & 0.098 & 0.063 & 0.029 & -0.004 \\
\hline 0.40 & 0.722 & 0.569 & 0.378 & 0.214 & 0.102 & 0.041 & -0.020 & -0.080 \\
\hline 0.50 & 0.722 & 0.551 & 0.349 & 0.193 & 0.102 & 0.014 & -0.074 & -0.161 \\
\hline 0.60 & 0.719 & 0.530 & 0.316 & 0.167 & 0.098 & -0.017 & -0.132 & -0.246 \\
\hline 0.70 & 0.711 & 0.504 & 0.280 & 0.138 & 0.089 & -0.053 & -0.194 & -0.335 \\
\hline Average Correlation & 0.710 & 0.566 & 0.379 & 0.213 & 0.090 & 0.042 & -0.006 & -0.053 \\
\hline \multirow[t]{2}{*}{$\begin{array}{c}\text { Volatility Impact } \\
\rho_{70 \%}-\rho_{10 \%}\end{array}$} & 0.015 & -0.094 & -0.159 & -0.116 & 0.012 & -0.149 & -0.311 & -0.472 \\
\hline & \multicolumn{8}{|c|}{ Panel B: Results Based on the Constant Coefficient Model } \\
\hline Average Correlation & 0.715 & 0.552 & 0.350 & 0.185 & 0.064 & 0.018 & -0.029 & -0.075 \\
\hline $\begin{array}{c}\text { Volatility Impact } \\
\rho_{70 \%}-\rho_{10 \%}\end{array}$ & -0.083 & -0.141 & -0.162 & -0.129 & -0.009 & -0.163 & -0.317 & -0.470 \\
\hline
\end{tabular}

Notes: This table shows the numerical values of predicted correlations based on the estimated Fixed Effects Model and Constant Coefficient Model of Table 3 with the average VIX value of 22.37. Volatility and the distance to default are defined in Table 4. Volatility impact, $\left(\rho_{70 \%}-\rho_{10 \%}\right)$, is obtained as the difference between predicted correlations given the distance to default. 


\section{Table 6}

\section{Determinants of the Correlation (Asymmetric Correlation and Moving Average Equity Volatility)}

\begin{tabular}{|c|c|c|c|c|c|c|c|}
\hline & & \multicolumn{3}{|c|}{$\begin{array}{c}\text { Panel A: } \\
\text { Asymmetric VECH Correlations }\end{array}$} & \multicolumn{3}{|c|}{$\begin{array}{c}\text { Panel B: } \\
\text { Moving Average Equity Volatility }\end{array}$} \\
\hline & & \multicolumn{2}{|c|}{$\begin{array}{l}\text { Corrected for Serial } \\
\text { Dependence }\end{array}$} & \multirow{2}{*}{$\begin{array}{c}\text { No } \\
\text { Correction } \\
\text { p-value }\end{array}$} & \multicolumn{2}{|c|}{$\begin{array}{l}\text { Corrected for Serial } \\
\text { Dependence }\end{array}$} & \multirow{2}{*}{$\begin{array}{c}\text { No } \\
\text { Correction } \\
\text { p-value }\end{array}$} \\
\hline & & Coefficient & p-value & & Coefficient & p-value & \\
\hline Distance to Default $\left(D D_{i t}\right)$ & $(\mathrm{H} 2)$ & -0.019 & 0.461 & 0.004 & -0.076 & 0.000 & 0.000 \\
\hline Distance to Default Squared $\left(D D_{i t}{ }^{2}\right)$ & $(\mathrm{H} 2)$ & 0.000 & 0.567 & 0.031 & 0.002 & 0.017 & 0.000 \\
\hline $\mathrm{I}(D D<0.8)$ & $(\mathrm{H} 2)$ & 0.829 & 0.000 & 0.000 & 0.555 & 0.000 & 0.000 \\
\hline $\mathrm{I}\left(0.8 \leq D D_{i t}<1.8\right)$ & $(\mathrm{H} 2)$ & 0.733 & 0.000 & 0.000 & 0.416 & 0.000 & 0.000 \\
\hline $\mathrm{I}\left(1.8 \leq D D_{i t}<2.8\right)$ & $(\mathrm{H} 2)$ & 0.533 & 0.000 & 0.000 & 0.306 & 0.000 & 0.000 \\
\hline $\mathrm{I}\left(2.8 \leq D D_{i t}<3.8\right)$ & $(\mathrm{H} 2)$ & 0.273 & 0.000 & 0.000 & 0.168 & 0.000 & 0.000 \\
\hline Equity Volatility $\left(V_{i t}\right)$ & (H3) & 1.155 & 0.001 & 0.000 & 0.287 & 0.067 & 0.000 \\
\hline Equity Volatility Squared $\left(V_{i t}^{2}\right)$ & (H4) & -0.197 & 0.001 & 0.000 & -0.015 & 0.656 & 0.438 \\
\hline Equity Volatility $\times D D_{i t}$ & (H4) & -0.250 & 0.000 & 0.000 & -0.068 & 0.003 & 0.000 \\
\hline Equity Volatility × I $\left(D D_{i t}<0.8\right)$ & $(\mathrm{H} 4)$ & -1.132 & 0.001 & 0.000 & -0.494 & 0.002 & 0.000 \\
\hline Equity Volatility $\times \mathrm{I}\left(0.8 \leq D D_{i t}<1.8\right)$ & (H4) & -1.097 & 0.000 & 0.000 & -0.411 & 0.001 & 0.000 \\
\hline Equity Volatility $\times \mathrm{I}\left(1.8 \leq D D_{i t}<2.8\right)$ & $(\mathrm{H} 4)$ & -0.938 & 0.000 & 0.000 & -0.394 & 0.001 & 0.000 \\
\hline Equity Volatility × I $\left(2.8 \leq D D_{i t}<3.8\right)$ & $(\mathrm{H} 4)$ & -0.549 & 0.002 & 0.000 & -0.277 & 0.002 & 0.000 \\
\hline \multicolumn{8}{|l|}{$\operatorname{VIX}\left(v_{t}\right)$} \\
\hline VIX x Distance to Default $\left(v_{t} D D_{i t}\right)$ & & 0.003 & 0.000 & 0.000 & 0.002 & 0.000 & 0.000 \\
\hline VIX x Equity Volatility $\left(v_{t} V_{i t}\right)$ & & 0.007 & 0.004 & 0.000 & 0.006 & 0.000 & 0.000 \\
\hline Intercept & & -0.166 & 0.237 & 0.000 & 0.098 & 0.219 & 0.000 \\
\hline
\end{tabular}

Notes: This table reports the results relating to hypotheses $\mathrm{H} 2$ to $\mathrm{H} 4$. The models are estimated using fixed period effects (VIX is dropped because of the perfect multicollinearity) and the constant coefficient (i.e., no effects), with and without correction for serial dependence. The estimated model is equation (13). In Panel A, the dependent variable, $\mathrm{C}_{\mathrm{it}}$, is the conditional correlation estimated from the asymmetric $\operatorname{VECH}(1,1)$ from equation (5), and equity volatility, $V_{\mathrm{it}}$, is estimated using a GARCH $(1,1)$ model. In Panel B, the EBR conditional correlation estimated from the symmetric VECH $(1,1)$ from equation (4), and equity volatility, $V_{i t}$, are based on a moving average estimate. The Distance to Default, $D D_{\text {it }}$, is obtained from equation (10), and I(.) is an indicator function that equals 1 if the argument is true and zero otherwise. The selection of dummy variable sets is described in the Appendix. 
Table 7

\section{Determinants of the Correlation with Controls for Asset Value, Bond Issue Value and Bond Duration}

\begin{tabular}{|c|c|c|c|c|c|c|c|}
\hline & & \multicolumn{3}{|c|}{ Panel A: Fixed Effects Model } & \multicolumn{3}{|c|}{ Panel B: Constant Coefficient Model } \\
\hline & & \multicolumn{2}{|c|}{$\begin{array}{l}\text { Corrected for Serial } \\
\text { Dependence }\end{array}$} & \multirow{2}{*}{$\begin{array}{c}\text { No } \\
\text { Correction } \\
\text { p-value }\end{array}$} & \multicolumn{2}{|c|}{$\begin{array}{l}\text { Corrected for Serial } \\
\text { Dependence }\end{array}$} & \multirow{2}{*}{$\begin{array}{c}\text { No } \\
\text { Correction } \\
\text { p-value }\end{array}$} \\
\hline & & Coefficient & p-value & & Coefficient & p-value & \\
\hline Distance to Default $\left(D D_{i t}\right)$ & $(\mathrm{H} 2)$ & -0.011 & 0.630 & 0.103 & -0.006 & 0.794 & 0.397 \\
\hline Distance to Default Squared $\left(D D_{i t}{ }^{2}\right)$ & $(\mathrm{H} 2)$ & 0.000 & 0.865 & 0.571 & 0.000 & 0.959 & 0.869 \\
\hline $\mathrm{I}(D D<0.8)$ & $(\mathrm{H} 2)$ & 0.806 & 0.000 & 0.000 & 0.874 & 0.000 & 0.000 \\
\hline $\mathrm{I}\left(0.8 \leq D D_{i t}<1.8\right)$ & $(\mathrm{H} 2)$ & 0.670 & 0.000 & 0.000 & 0.685 & 0.000 & 0.000 \\
\hline $\mathrm{I}\left(1.8 \leq D D_{i t}<2.8\right)$ & $(\mathrm{H} 2)$ & 0.462 & 0.000 & 0.000 & 0.441 & 0.000 & 0.000 \\
\hline $\mathrm{I}\left(2.8 \leq D D_{i t}<3.8\right)$ & $(\mathrm{H} 2)$ & 0.251 & 0.000 & 0.000 & 0.240 & 0.001 & 0.000 \\
\hline Equity Volatility $\left(V_{i t}\right)$ & (H3) & 1.145 & 0.000 & 0.000 & 0.869 & 0.004 & 0.000 \\
\hline Equity Volatility Squared $\left(V_{i t}{ }^{2}\right)$ & (H4) & -0.206 & 0.000 & 0.000 & -0.230 & 0.000 & 0.000 \\
\hline Equity Volatility $\times D D_{i t}$ & (H4) & -0.282 & 0.000 & 0.000 & -0.268 & 0.000 & 0.000 \\
\hline Equity Volatility $\times \mathrm{I}\left(D D_{i t}<0.8\right)$ & (H4) & -1.097 & 0.000 & 0.000 & -1.180 & 0.000 & 0.000 \\
\hline Equity Volatility $\times \mathrm{I}\left(0.8 \leq D D_{i t}<1.8\right)$ & (H4) & -0.999 & 0.000 & 0.000 & -1.003 & 0.000 & 0.000 \\
\hline Equity Volatility $\times \mathrm{I}\left(1.8 \leq D D_{i t}<2.8\right)$ & (H4) & -0.803 & 0.000 & 0.000 & -0.752 & 0.001 & 0.000 \\
\hline Equity Volatility $\times \mathrm{I}\left(2.8 \leq D D_{i t}<3.8\right)$ & (H4) & -0.509 & 0.002 & 0.000 & -0.481 & 0.005 & 0.000 \\
\hline $\operatorname{VIX}\left(v_{t}\right)$ & & & & & -0.020 & 0.000 & 0.000 \\
\hline VIX x Distance to Default $\left(v_{t} D D_{i t}\right)$ & & 0.002 & 0.000 & 0.000 & 0.002 & 0.000 & 0.000 \\
\hline VIX x Equity Volatility $\left(v_{t} V_{i t}\right)$ & & 0.005 & 0.012 & 0.000 & 0.015 & 0.000 & 0.000 \\
\hline Intercept & & -0.013 & 0.924 & 0.734 & 0.431 & 0.003 & 0.000 \\
\hline Asset Value Dummy 1 (smallest) & & -0.120 & 0.133 & 0.000 & -0.103 & 0.206 & 0.000 \\
\hline Asset Value Dummy 2 & & 0.022 & 0.674 & 0.030 & 0.035 & 0.509 & 0.001 \\
\hline Asset Value Dummy 3 & & -0.056 & 0.157 & 0.000 & -0.059 & 0.133 & 0.000 \\
\hline Asset Value Dummy 4 & & -0.074 & 0.035 & 0.000 & -0.078 & 0.024 & 0.000 \\
\hline Asset Value Dummy 5 & & -0.056 & 0.097 & 0.000 & -0.059 & 0.077 & 0.000 \\
\hline Asset Value Dummy 6 & & -0.036 & 0.264 & 0.000 & -0.035 & 0.280 & 0.000 \\
\hline Bond Value Dummy 1 (smallest) & & -0.063 & 0.207 & 0.000 & -0.067 & 0.183 & 0.000 \\
\hline Bond Value Dummy 2 & & 0.062 & 0.286 & 0.000 & 0.059 & 0.312 & 0.000 \\
\hline Bond Value Dummy 3 & & -0.045 & 0.464 & 0.000 & -0.049 & 0.438 & 0.000 \\
\hline Bond Value Dummy 4 & & -0.004 & 0.941 & 0.639 & -0.014 & 0.804 & 0.122 \\
\hline Bond Value Dummy 5 & & -0.024 & 0.620 & 0.003 & -0.028 & 0.562 & 0.001 \\
\hline Bond Value Dummy 6 & & -0.005 & 0.922 & 0.539 & -0.010 & 0.832 & 0.187 \\
\hline Bond Value Dummy 7 & & -0.020 & 0.670 & 0.008 & -0.023 & 0.625 & 0.003 \\
\hline Bond Value Dummy 8 & & 0.038 & 0.455 & 0.000 & 0.031 & 0.548 & 0.000 \\
\hline Bond Duration Dummy 1 (shortest) & & -0.060 & 0.028 & 0.000 & -0.029 & 0.218 & 0.000 \\
\hline Bond Duration Dummy 2 & & -0.001 & 0.961 & 0.783 & 0.003 & 0.898 & 0.477 \\
\hline Bond Duration Dummy 3 & & -0.031 & 0.133 & 0.000 & -0.022 & 0.282 & 0.000 \\
\hline
\end{tabular}

Notes: The table reports the results of an extended version of equation (13). The models are estimated using period fixed effects (VIX is dropped because of perfect multicollinearity) and a constant coefficient (i.e., no effects), with and without correction for serial dependence. The dependent variable, $\mathrm{C}_{\mathrm{it}}$, is the conditional correlation estimated from the symmetric VECH $(1,1)$ from equation (4). Equity volatility, $V_{\text {it }}$, is estimated using a GARCH $(1,1)$ model. Distance to default, $D D_{\mathrm{it}}$, is obtained from equation (10), and $\mathrm{I}($.) is an indicator function that equals 1 if the argument is true and zero otherwise. The Asset Value Dummies 1 to 6 take the value of 1 if the log of firm's asset value in millions of US dollars is less than 6 or between the two thresholds of 6, 7, 8, 9, 10, 11 (i.e., 403, 1097, 2981, 8103, 22026, 59874 million). The Bond Value Dummies 1 to 8 take the value of 1 if the log of bond issue value in millions of US dollars is less than 3.1 or between the two thresholds of 3.1, 3.6, 4.1, 4.6, 5.1, 5.6, 6.1, and 6.6 (i.e. 22, 37, 60, $99,164,270,446$ and 735 million). The Bond Duration Dummies 1 to 3 take the value of 1 if the bond duration is less than 3.7 or between the two thresholds od 3.7, 7.2, and 10.5 years. The selection of dummy variable sets is described in in the Appendix. 


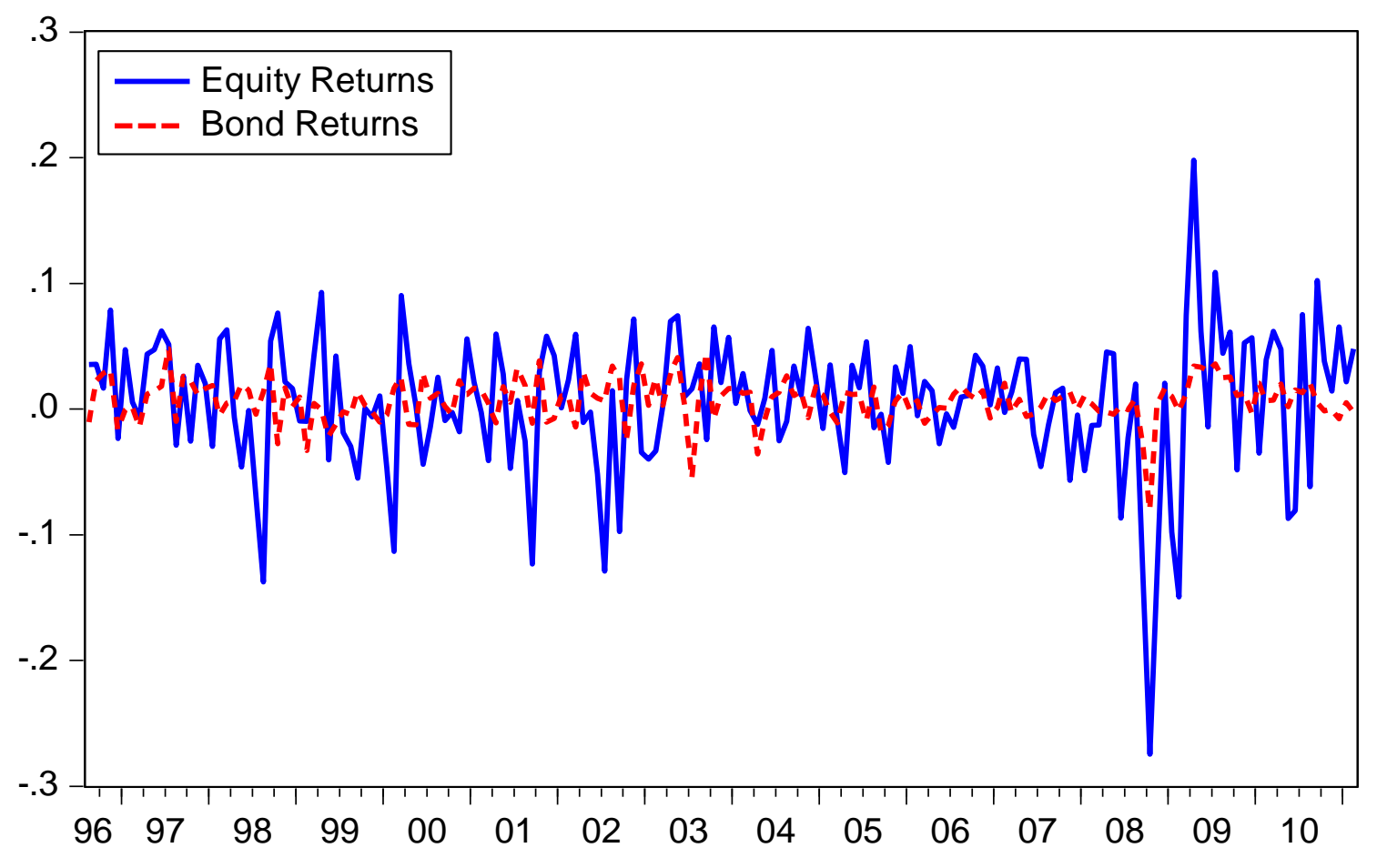

Figure 1. Time series of the cross sectional average of equity and bond returns 


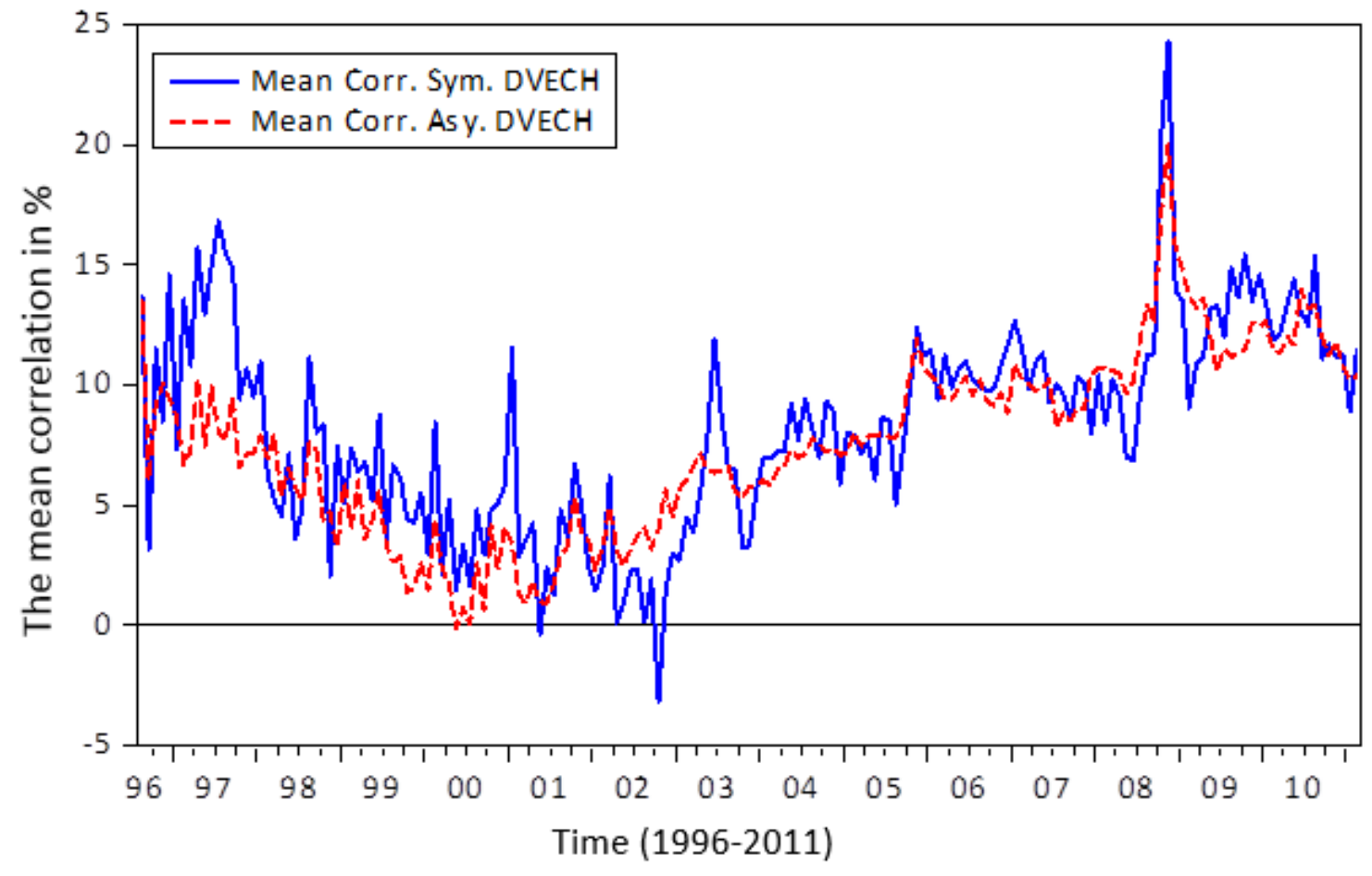

Figure 2. Time series of the cross sectional average of conditional correlation

Notes: The figure shows time series plots of monthly cross section averages of equity-bond conditional correlations estimated by the diagonal VECH models (4) and (5). 

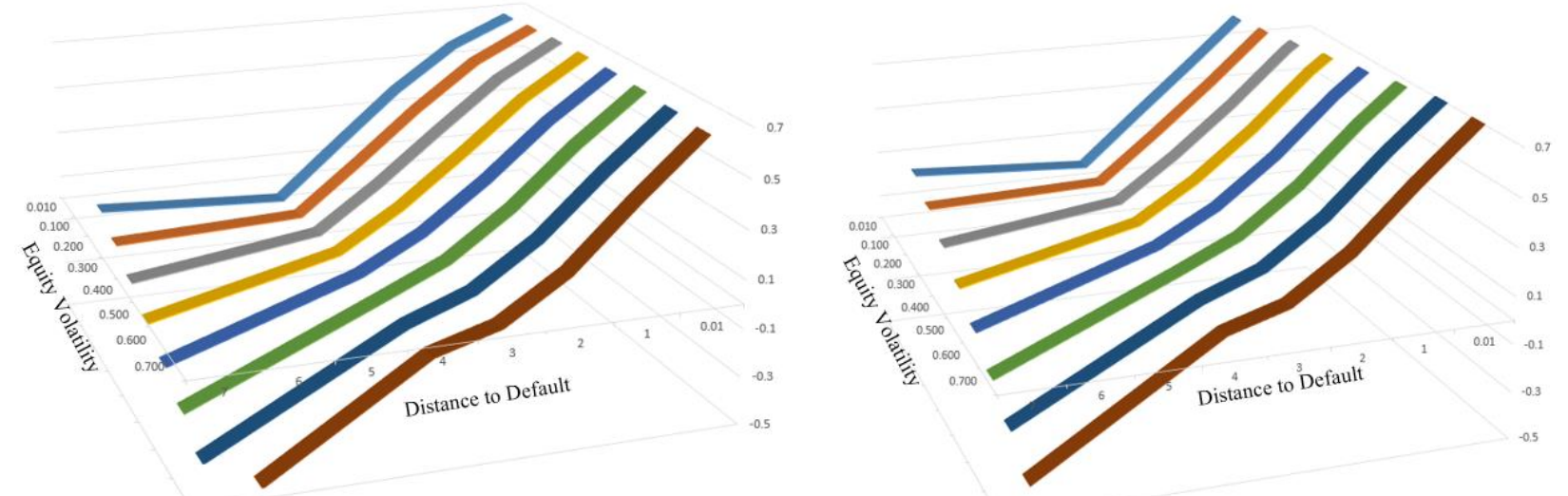

(a) Minimum VIX $=10.8$
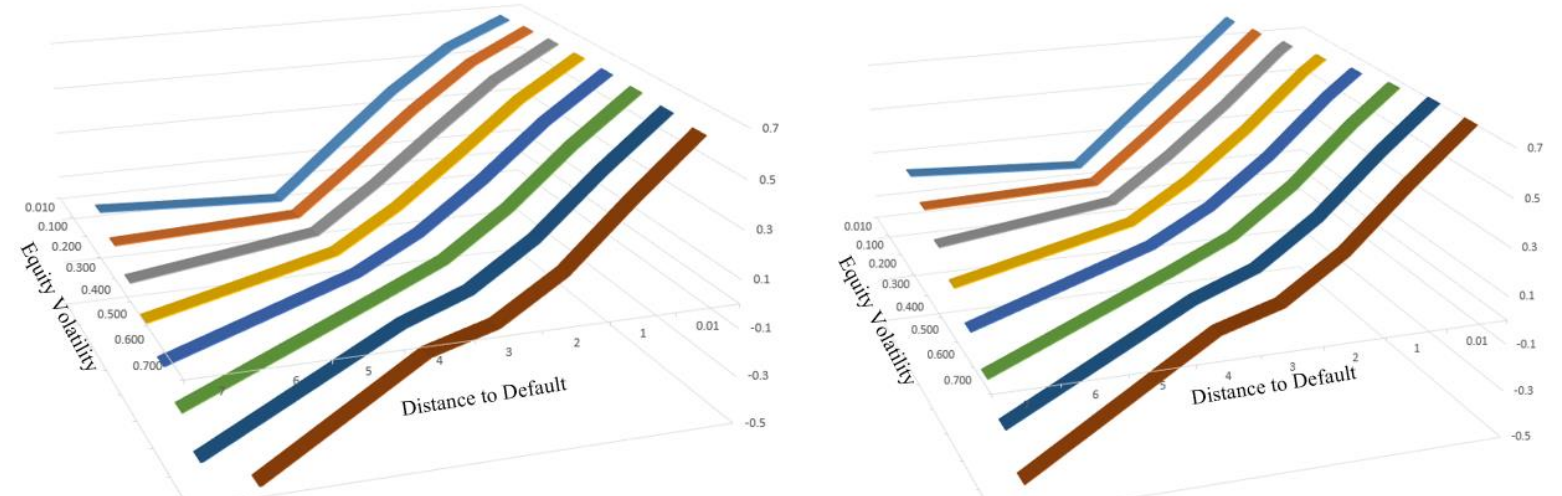

(b) Average VIX $=22.4$
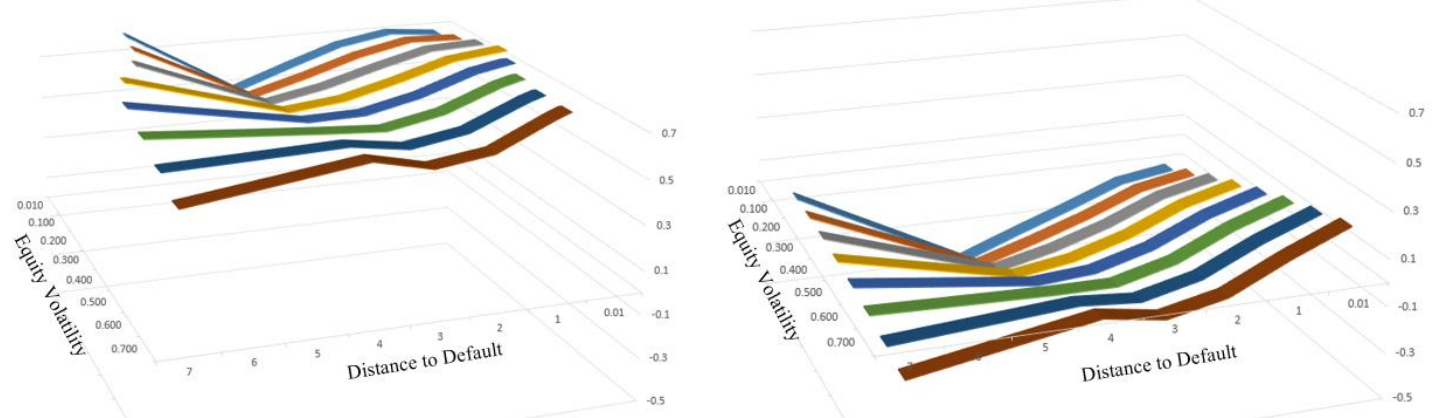

(c) Maximum VIX $=62.6$

Figure 3. The implied impact of equity volatility and credit risk on EBR correlation 
Notes: The figure shows EBR correlation for various volatility and distance to default combinations. The left hand side figures are based on the Fixed Effects Model and the right hand side figures are based on the Constant Coefficient Model (Table 4). 

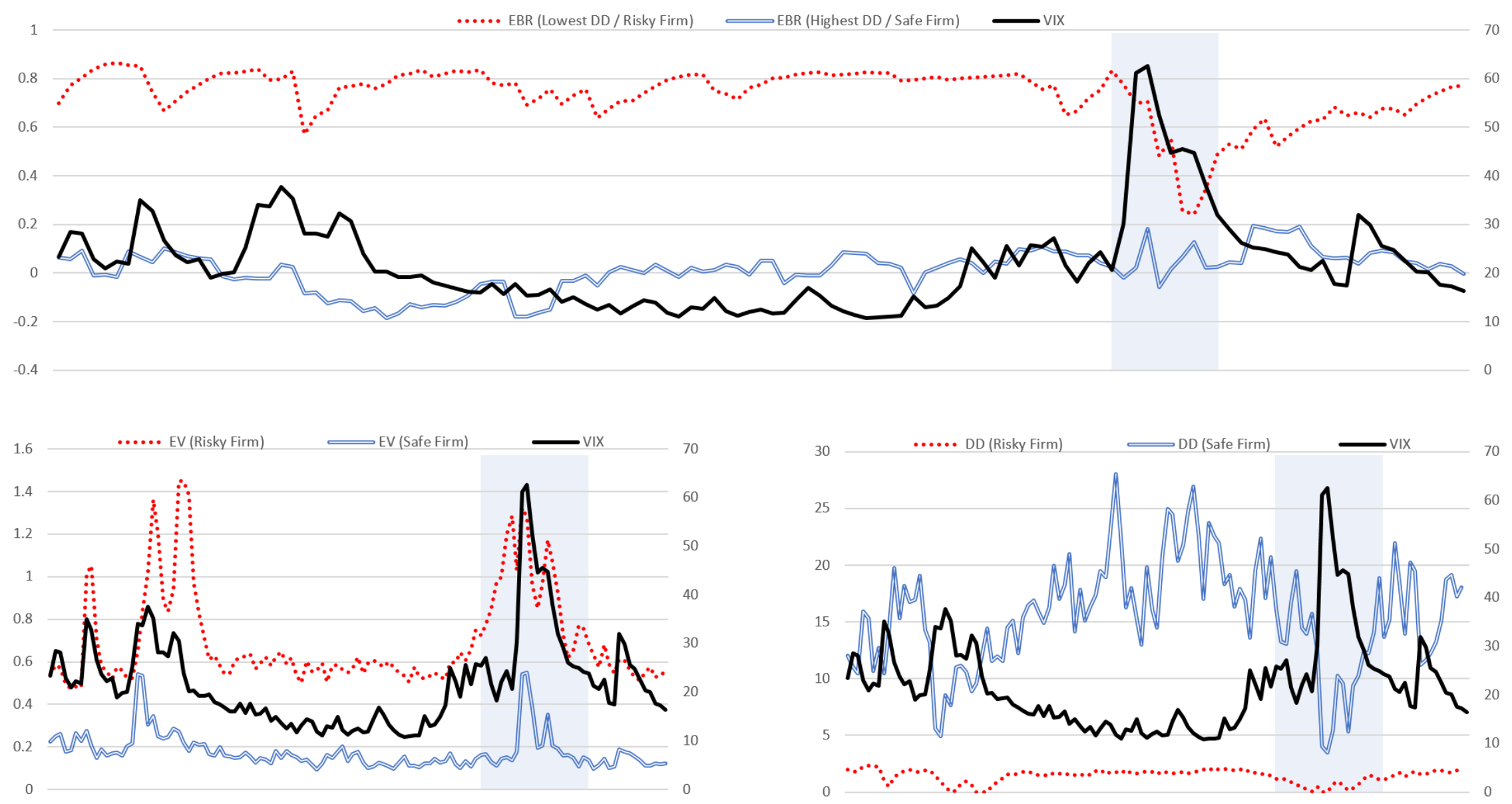

Note: The EV value (lowest DD/risky firm) for March 2003 was 2.16. It was set to the preceding month's value (1.45) to improve the visual impact of EV. The data are from January 2001 to December 2011. The VIX scale is on the right-hand side. The shaded area indicates the highest level of the VIX.

Figure 4. Monthly time series plots for the lowest (risky firm) and highest (safe firm) average DD firms 


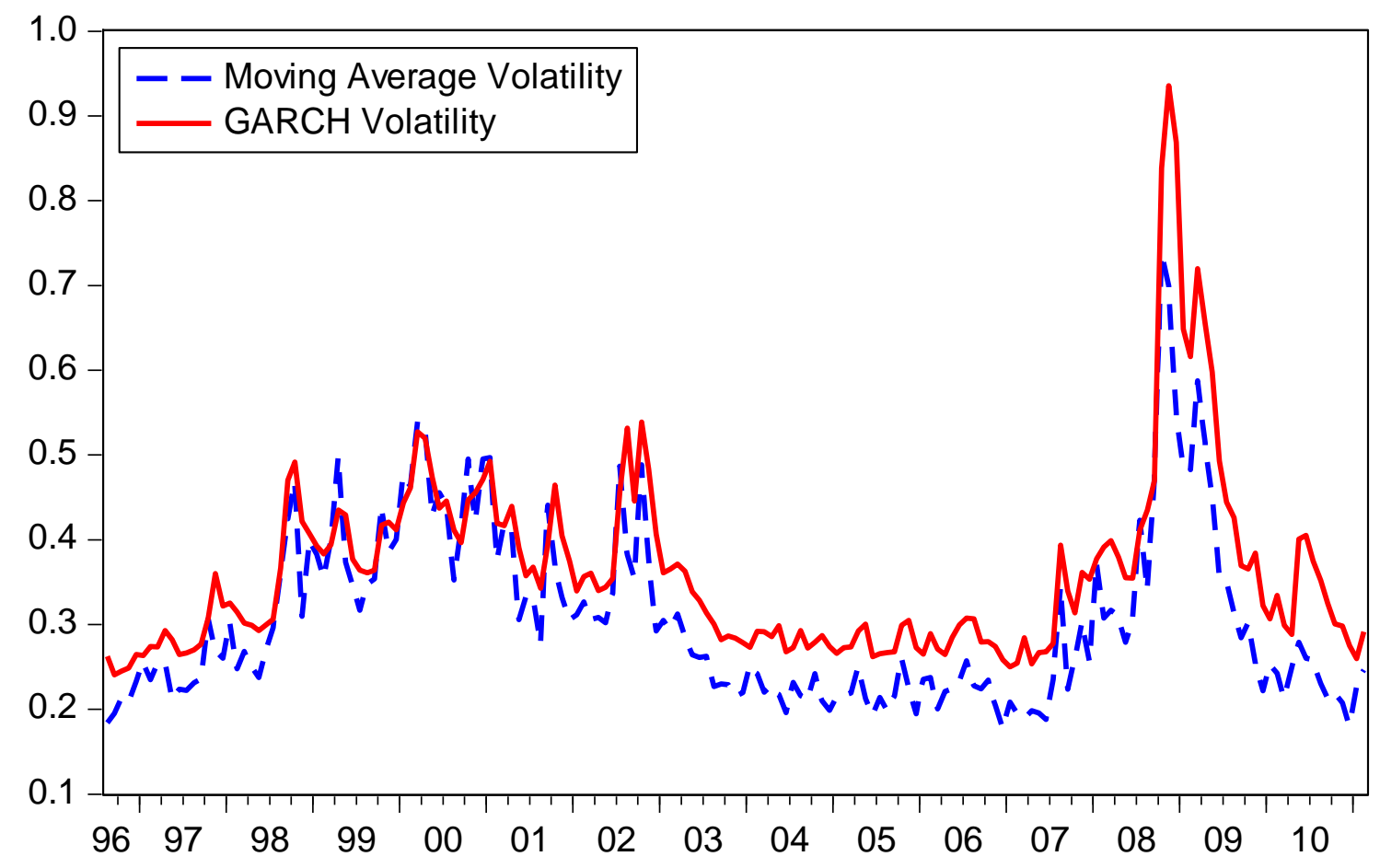

Figure 5. Time series of the cross-sectional average of equity volatility 